Article

\title{
Exploring the Roles of Local Mobility Patterns, Socioeconomic Conditions, and Lockdown Policies in Shaping the Patterns of COVID-19 Spread
}

\author{
Mauricio Herrera ${ }^{*}+$ (D) and Alex Godoy-Faúndez ${ }^{+}$(D) \\ Research Center on Sustainability and Strategic Resource Management, Faculty of Engineering, Universidad del \\ Desarrollo, Avenida Plaza 680, San Carlos de Apoquindo, Las Condes, Santiago de Chile, Chile; \\ alexgodoy@ingenieros.udd.cl \\ * Correspondence: mherrera@ingenieros.udd.cl \\ † These authors contributed equally to this work.
}

Citation: Herrera, M.; Godoy-Faúndez, A. Exploring the Roles of Local Mobility Patterns, Socioeconomic Conditions, and Lockdown Policies in Shaping the Patterns of COVID-19 Spread. Future Internet 2021, 13, 112. https:// doi.org/10.3390/fi13050112

Academic Editor: Paolo Bellavista with regard to jurisdictional claims in published maps and institutional affiliations.

\begin{abstract}
The COVID-19 crisis has shown that we can only prevent the risk of mass contagion through timely, large-scale, coordinated, and decisive actions. This pandemic has also highlighted the critical importance of generating rigorous evidence for decision-making, and actionable insights from data, considering further the intricate web of causes and drivers behind observed patterns of contagion diffusion. Using mobility, socioeconomic, and epidemiological data recorded throughout the pandemic development in the Santiago Metropolitan Region, we seek to understand the observed patterns of contagion. We characterize human mobility patterns during the pandemic through different mobility indices and correlate such patterns with the observed contagion diffusion, providing data-driven models for insights, analysis, and inferences. Through these models, we examine some effects of the late application of mobility restrictions in high-income urban regions that were affected by high contagion rates at the beginning of the pandemic. Using augmented synthesis control methods, we study the consequences of the early lifting of mobility restrictions in low-income sectors connected by public transport to high-risk and high-income communes. The Santiago Metropolitan Region is one of the largest Latin American metropolises with features that are common to large cities. Therefore, it can be used as a relevant case study to unravel complex patterns of the spread of COVID-19.
\end{abstract}

Keywords: mobility data; data-driven models; augmented synthetic control method

\section{Introduction}

Often the models used by experts (from whom decision-makers get their main advice) have been weighted mainly on a forecasting epidemiological perspective rather than considering the intricate web of causes and drivers behind observed patterns of contagion diffusion. The context created by epidemiological, socioeconomic, and human mobility aspects of the COVID-19 spread can be viewed as a complex adaptive system [1-3]. Therefore, these actions (e.g., lockdowns) could have many unexpected ramifications $[4,5]$.

The role of urban proximity, socioeconomic facts, and human mobility in pandemics has seen renewed attention in the context of COVID-19 [6-11]. Human mobility plays an important role in the spread of contagions, and its study helps in understanding the patterns of COVID-19 outbreaks and their subsequent spread [12-16]. Mobile sensing data, on the other hand, can be used to measure/describe human mobility [17-21].

Mobility restrictions have been an important part of the response to the ongoing COVID-19 pandemic [22-26]. They have been essential for preventing massive outbreaks and reducing systemic stress in hospitals and clinics. However, implementing these restrictions not only infringes on people's rights, but it can also be cumbersome and expensive $[5,27,28]$. Therefore, it is vitally important to understand the effectiveness of such measures in controlling the spread of contagion. 
Numerous authors have addressed the issue of mobility restrictions both theoretically and empirically [10,29-31]. Most of these studies have focused on the role of international travel restrictions on the rate of spread and have shown that these restrictions can reduce the rate at which a disease spreads from the source of infection. However, researches on local propagation in communities or through public transport in cities are less common. One of these works on local transmission is that of Espinoza B. et al. [32], which focused on dimensions of epidemics other than contagion rate, such as duration or final size in individual communities, also taking into account the role of availability and quality of health care. These authors showed that, in certain cases, the mobility restriction measures are counterproductive for low-income urban sectors.

Despite this growing literature, the channels through which the virus spread between urban sectors, how public policies to mitigate the risk really affect this spread, and the spillovers of these actions on broader community transmission remain unclear.

The COVID-19 pandemic has highlighted the critical importance of generating rigorous evidence for decision-making, and actionable insights from all the available data (e.g., [33-37]). In this research study, by using recorded human mobility data and socioeconomic data (e.g., income, wealth, public health infrastructure, cultural practices), we aim to understand/explain the observed regional patterns in the evolution of the pandemic. This work is closely linked to a rapidly growing literature using mobile phone geolocation and other mobile sensing data to assess the spread of COVID-19 [12,16], and it also addresses the issue of public policies related to mobility restrictions and their heterogeneous effectiveness to curb the spread of the virus.

The Santiago Metropolitan Region (MR) is one of the largest metropolises in Latin America. Many mobility patterns and inequities on socioeconomic conditions that are common to large cities are observed in MR. Therefore, MR can be used as a good case study to unravel complex patterns of COVID-19 spread. To provide some context, MR holds $8,125,072$ people, accounting for approximately $42 \%$ of the country's population, and has a high population density of 527.5 people per $\mathrm{km}^{2}$. This makes the MR the main focus of confirmed cases in the country, as of 29 October 2020, accounting for 57\% of the COVID-19 cases (in the first months of the pandemic, this percentage was much higher; for example, as of 15 May, it was 74\%) [38].

We can further argue that Latin American countries are unable to adopt some of the measures that high-income countries have implemented due to lower availability of resources and being less prepared [39]. Therefore, it may be interesting to learn details about the different approaches that developing countries like Chile have implemented to deal with the pandemic.

Latin American countries have managed to control the pandemic through different strategies. In the cases of Argentina, Bolivia, Colombia, and Peru, for example, total quarantine was established when the number of confirmed cases was still low. Some of these countries have been more successful compared to others, but most of them have suffered long periods of restricted mobility, showing clear signs of fatigue and successive outbreaks of infection.

The Chilean government's strategy in the initial phase of the pandemic was to close educational establishments, close all non-essential businesses, and declare a state of emergency with a night curfew. This partially restricted people's mobility for several specific hours during the night. Furthermore, in the capital Santiago, the government used relatively massive testing and implemented a dynamic quarantine strategy by dividing the capital into sectors delimited by communes (communes are administrative boundaries or fundamental administrative units in Chile), and further dividing and isolating specific geographic locations of those communes. These lockdowns were periodically reassessed and lifted, prolonged, or expanded depending on the active cases in the sectors. After this first phase characterized by dynamic quarantines, the government declared a prolonged quarantine practically all of the MR as of 15 May 2021. From this quarantine, the communes gradually left. The third phase of this period of the pandemic was given by the 
implementation of the plan called "Step by Step" [40]. These interventions have successfully limited the spread of COVID-19 in high-income MR communes; however, in the low-income communes, the effectiveness of these control measures has been significantly less pronounced.

This study could contribute to the analysis of the management that different countries have made of the crisis and its very dissimilar results. In particular, in the case of Chile, and even though the government used the same tools (early border closures, confinement policies, and massive tests) as other countries with more success in controlling the pandemic, such as New Zealand or Vietnam, the result of its handling was considered among the ten worst in the world [41]. Therefore, we ask ourselves, what are the reasons for this?

PNUD-Grandata [42] (one of our data providers) has aggregated information of a sizable sample of smartphone users' locations across twelve Latin American countries. In this paper, we used part of this data registered for the Metropolitan Region of Santiago de Chile to describe/analyze mobility patterns in urban sectors and their influences on COVID-19 spread. We complement these mobility data with (1) counts of coronavirus cases at the communal level from the COVID-19 data repository of the Ministry of Sciences [43], (2) mobility data from the origin-destination matrices obtained from the metropolitan public transport [44], (3) mobility indices calculated from the cell phone tower network [45,46], and (4) publicly available socioeconomic data of MR communes that include income, education, health-care access, cultural practices, and so on [47].

The proposed methodology and the tools used in this work are not exclusive to the case of Chile and would also contribute to answering several related questions, for example: What is the precise moment to apply the confinement policy, to what extent, and when to lift these restricted mobility measures? What are the possible results of not applying the mobility restrictions? How could these modifications affect the spread of the virus? How do socioeconomic conditions influence this spread?

\section{Materials and Methods}

The first source of data used in this work is that collected by Grandata (this dataset is used in the context of the UNDP LAC call "Exploring the impact and response to the COVID-19 pandemic in Latin America and the Caribbean using mobility data" sponsored (no funding, data only) by the Research Team/Policy Response Office of the Chief Economist, Regional Office for Latin America and the Caribbean.) [42]. Since 1 March 2020, geolocation events of smartphone owners were recorded by the Grandata group, using a MAID (Mobile Advertising ID) "hash". These events track the mobility patterns of smartphone users for a considerable sample of the population of twelve Latin American countries (In the case of the Santiago Metropolitan Region, a sample of approximately $10 \%$ of the population is considered). To distinguish only individuals for which there are enough data, unique users with less than 10 daily geolocation events (displacements or changes in the user's geolocation) or those whose daily events only took place within $8 \mathrm{~h}$ were excluded from the dataset. The average number of geolocation events of the individuals in the remaining data sample is 130, recording a piece of valuable information about each user's mobility history. For unique users, the mode of their geolocation events (or the location most frequented) was assumed to be their residency, and all other events are considered outings or "out-of-home" events. All home events were then deleted, and the remaining ones are aggregated for a specific area or region to create mobility indicators. These geo-referenced data were aggregated for hexagonal areas constructed using the $\mathrm{H} 3$ geospatial indexing system [48]. For each area, all the outing events that took place within it, irrespective of where the user's home is located, were added up in that area's mobility indicators.

In essence, $\mathrm{H} 3$ works by dividing the surface of the earth into a number of homogeneous hexagon tiles, each one of which is indexed using a hierarchical linear index. This system has an advantage over the traditional longitude-latitude coordinate system, since it better fits the world's curvature, offering more precise spatial representation. Mobility 
data are considered at different resolution levels. The H3 system includes up to 15 levels of precision, the 15th level dividing the map in the smallest hexagons possible (the most precise), and the 0 levels using the largest ones (the least precise). We used level 6 hexagons in the $\mathrm{H} 3$ geospatial system, which spans $0.74 \mathrm{~km}^{2}$. Each hexagon's index serves both as a unique identifier, as well as a geospatial coordinate. The H3 website [48] includes documentation on how to obtain longitude and latitude coordinates from an $\mathrm{H} 3$ index and vice versa.

Mobility indicators for the hexagons are not indexes, but rather the corresponding hexagon's percentile placement in the mobility distribution, counting all hexagons within the MR. From now on we will call it "score". For the analysis, the MR is covered with hexagons, in each of them, the score is determined from the geolocation events that occur inside. The values of these scores indicate daily percentiles of the movements/mobility that take place within the area marked by the hexagon. The percentiles are calculated with respect to the score distribution accounting for all the geolocation events given in all the hexagons that cover the MR. In panel C of Figure 1, these scores are plotted for a given working day. The highest scores/percentiles are in blue, while the lowest is yellow, passing through a range of greens.

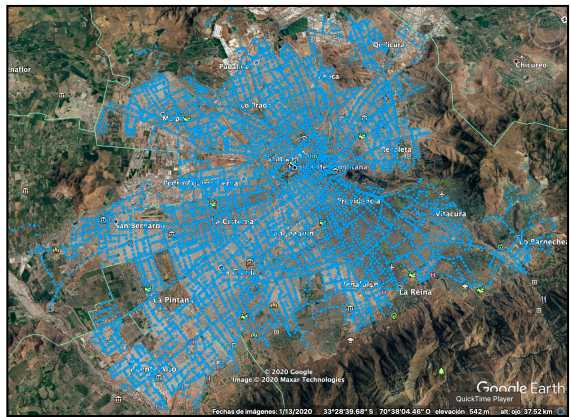

(A)

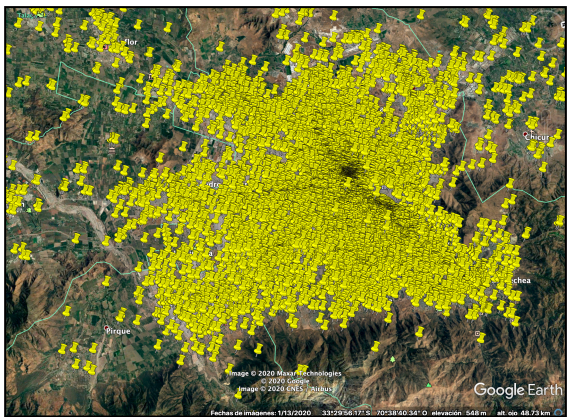

(B)

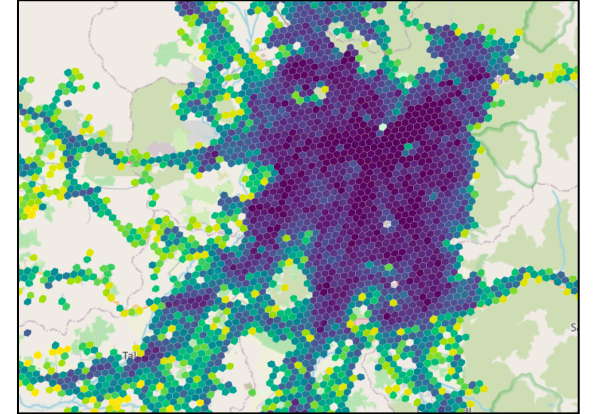

(C)

Figure 1. Capturing mobility patterns of MR through three sensing methodologies. Panel (A) shows around 12,000 bus stations in the MR public transport network. The O-D matrices are estimated by the flow of passengers between these bus stations. Panel (B) indicates the network of cell phone antennas that provide coverage in the MR. The mobility index is determined by the flow of mobile phone users and the records they leave on the antennas covering the service while they are moving. Panel (C) shows level-6 hexagons covering the MR on a given day. The highest scores/percentile are in blue, while the lowest is yellow, passing through a range of greens.

The second source of mobility data comes from the payment smart-card use in the MR public transport system and the buses/Metro geo-coded information [44]. Every week, over 35 million smart-card transactions are recorded in the MR public transport. Throughout the week, similar numbers of transactions per working day of approximately six million are observed. During the weekend, this number falls to less than four million on Saturday and less than 2.5 million on Sunday [49]. Transactions are recorded in a database that contains information about the operator and the time when the transaction was made. Each passenger has to make a transaction by putting the smart-card close to a payment device when entering a bus, bus station, or Metro station. Each payment device has an id, and it is associated with a bus, a Metro station, or a bus station. The information recorded for each transaction includes the smart-card id and type, code of bus or site where the transaction was made, time, date, and amount of money paid. Another database contains geo-coded information about all the buses, such as latitude, longitude, time, date, and instant speed. Each bus is identified by a plate number and an operator code. The position is available every $30 \mathrm{~s}$. Every week of data contains approximately 80 million GPS observations. By matching the Transactions and Positions databases through bus plates or Metro/Bus-station codes and times, it was possible to identify the position where 
the transaction was made in $98.5 \%$ of the cases. The ADATRAP software (developed by the Universidad de Chile and the Metropolitan Public Transport Directory) reconstructs the trip chain of users behind smart-cards by estimating the destination points from the information available, building in this way the origin-destination (O-D) matrices (see $[49,50]$ for details of this methodology). Around 12,000 bus stations are considered (see Figure 1A). With these data, the trips between communes can be estimated (see Figure 8).

The third source of mobility data used in this paper comes from the ubiquitous infrastructure provided by the cell phone network (see Figure 1B). This network is a set of geolocated cell towers (base transceivers stations) that provide cellular phone service to the MR [51]. Each cell tower has a latitude and a longitude-its geolocation-and gives cellular coverage to an area/sector. We assume that each sector is a 2-dimensional non-overlapping polygon that can be geometrically modeled. The exact position of the cell phone user within each sector is unknown. When a cellular device (PHONE_ID) interacts with the network, there is a record of its connection to the antenna (CELL_ID) and a timestamp (EVENT_TM) of when this happened. The passage from one antenna to another is considered a trip. We used publicly available data records from the TelefónicaMovistar company (according to the Telecommunications Secretary (Subtel) of the Ministry of Transport and Telecommunications, there are 25,731,160 cell phone lines in Chile, and the Telefónica-Movistar company owns about $28 \%$ of them [52]). The available data includes the analysis of records of 1.4 million users. [45].

Two indices were calculated $[46,53]$, the internal mobility index MobIn, which measures only trips within a commune. That is, the changes in the antennas and their respective locations, which give coverage to the cell phone service when the user moves within the limits of the commune. The MobIn corresponds to how many trips (antenna transitions) were made within a specific commune normalized by the number of devices (cell phones) residing in the commune. The external mobility index MobOut, for its part, estimates the trips of users crossing the commune border. This way, the MobOut for the commune A is the number of trips entering or leaving $\mathrm{A}$, normalized by the number of devices in $\mathrm{A}$. The sum of these two indices is called the Mobility Index = MobIn + MobOut.

To assess socioeconomic indicators of Santiago Metropolitan communes, we used census data and a more ad hoc, publicly available, data source-the Territorial Well-being Index of 2012 [47], which indexes the mean income of every census administrative unit down to the block level, of which Santiago has 39,901.

Another source of data is the publicly available COVID-19 cases, registered on a daily basis by the Ministry of Sciences [43].

Using observable variables obtained directly from the data, for example, (1) the number of antenna transitions recorded by locations of successive cell towers that cover the user's cell phone service during trips in the studied sector, (2) the "out-of-home" events measured in each hexagon [48] covering the studied sector (using the H3 geospatial indexation system; see Section 3.1), we characterized the observed mobility patterns in the MR (in principle, the models, methodology, and analyses in this work can be used regardless of the region, and the only likely impediment is the availability of similar data). We also considered (3) the commune's socioeconomic conditions by using census data, incorporating, in this way, several economic and demographic indicators into the analysis.

We built relationships (regressions) between these variables and analyzed causal inferences. The number of COVID-19 cases was treated with these regression models along with synthetic and counterfactual control models applied to case and mobility time series. We searched for correlations between mobility patterns, along with socioeconomic drivers, and the observed spread patterns of COVID-19. We also explored the impact produced by successive policies of confinement. The main goal is to make a consistent, scientifically validated, data-supported narrative to explain the MR patterns of the pandemic using data on mobility, socioeconomic conditions, and public policies of confinement. 


\section{Results}

\subsection{Santiago Metropolitan Region Mobility Patterns}

The Grandata mobility data were used to characterize the mobility patterns of the communes (basic geographic units/sectors in our analysis) of the MR. We recall from Section 2 that this mobility data contain logs of geolocation events tracking mobility patterns of the smartphone by using Mobile Advertising ID hashes [42]. Mobility data were constructed for hexagon shapes using the $\mathrm{H} 3$ geospatial system [48]. The geolocation events were summed for each area covered by hexagons. The score for each hexagon area consists of the hexagon's percentile placement in the mobility distribution ("out-of-home" event distribution) for each day and taking into account all other hexagons in the MR. Figure $1 \mathrm{C}$ shows the scores or percentiles for hexagons covering the MR.

The MR is made up of 52 communes. We assume that each hexagon is a kind of "sensor" to measure the mobility of some commune area. Each commune is covered by a specific number of sensor-hexagons (the MR is covered by a total of 11.853 hexagons) that measure the mobility of the area for 249 days (time interval between 2 March 2020 and 1 November 2020), thus generating a time series with mobility scores. We average the daily scores of all the sensor-hexagons that make up each commune as a proxy for the mobility of the communes during the day. In this way, we obtain 52 time series corresponding to the average scores of each commune during the study time interval. Figure 2 shows these average scores (for simplicity, we will continue to call this value score although it is understood that it is constructed as the average of the scores of the hexagons that cover the commune) time series for a sample of 16 MR communes (the choice of a sample of size 16 is only to obtain a better visualization, and the analysis is done with all the communes of the MR).

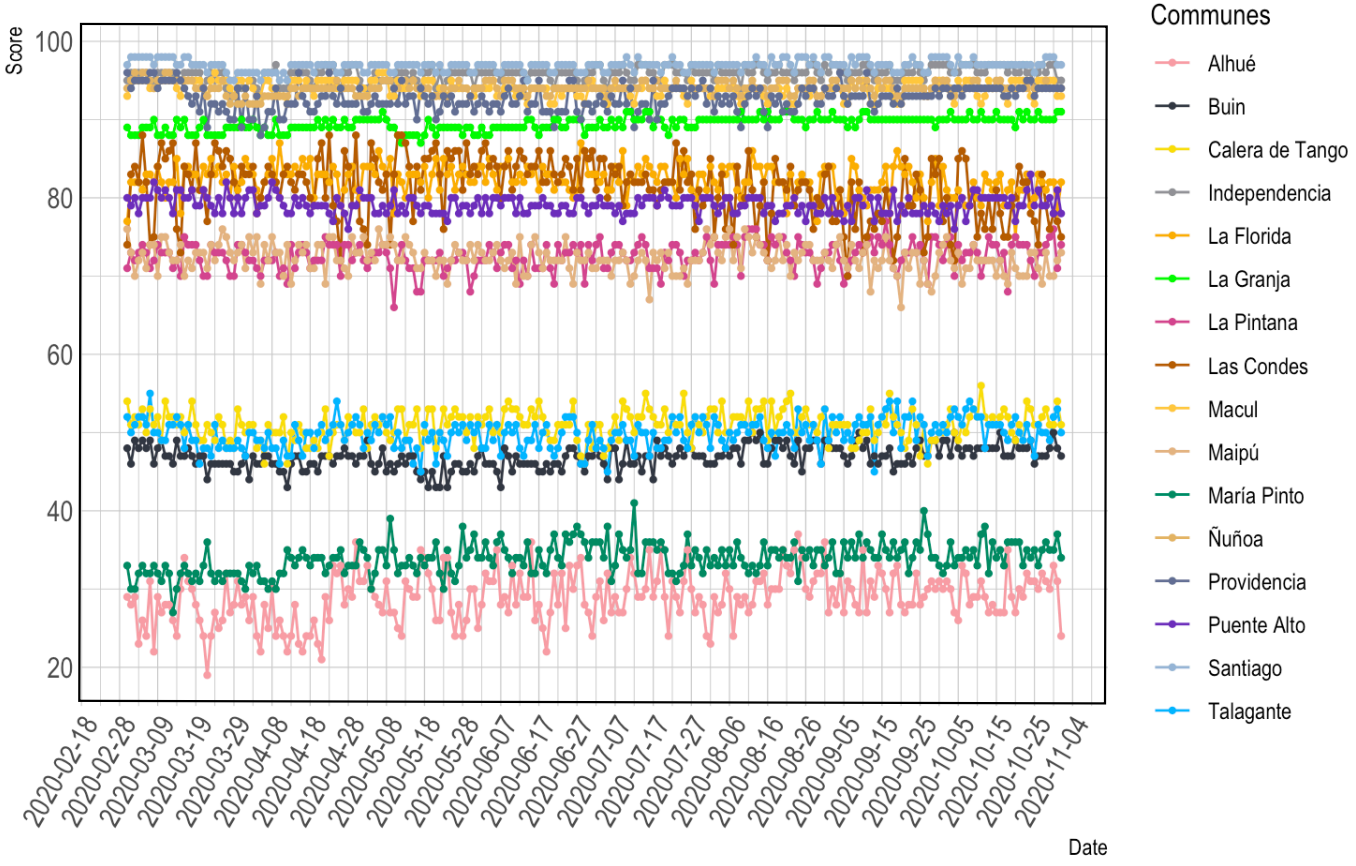

Figure 2. Time series for the average mobility scores of a sample of 16 Metropolitan Region communes.

We constructed the time series from the average of the scores of all the hexagons that cover each commune daily. This mean score by construction may contain space-time fluctuations. Moreover, its values over time may be out of phase concerning the scores of other communes, even although globally these communes could have similar mobility patterns. To discover similar patterns in the time series of the commune mobility scores, it is important to define a measure of similarity/distance between these series that considers 
this possible distortion in the time axis. A distance measure called Dynamic Time Warping (DTW) is a mapping of points between a pair of time series, designed to minimize the pairwise Euclidean distance. This method allows non-linear alignments between two series to accommodate similar sequences, and it is becoming recognized as one of the most accurate similarity measures for time series data [54-57]. Indeed, DTW is a popular technique for comparing time series, providing both a distance measure that is insensitive to local compression and stretches and the warping, which optimally deforms one of the two input series onto the other. The rationale behind DTW is, given two time series, to stretch or compress them locally to make one resemble the other as much as possible (another advantage, concerning the methods based on the Euclidean distance, is that DTW allows the comparison between time series that may eventually have different numbers of components).

To capture the mobility patterns of the MR, we used cluster analysis for time series with DTW distance. For this analysis, we used the R package dtw [58].

Figure 3 shows a dendrogram, the result of applying a hierarchical cluster analysis with DTW distance and average linkage method, where the five-clusters solution has been highlighted (we also used the PAM and Fuzzy c-means method included in the dtwclust package [59], but the Hierarchical method showed better regularity in the structure of the clusters). In essence, the analysis recognizes similar behaviors of communes according to the value of the mobility scores.

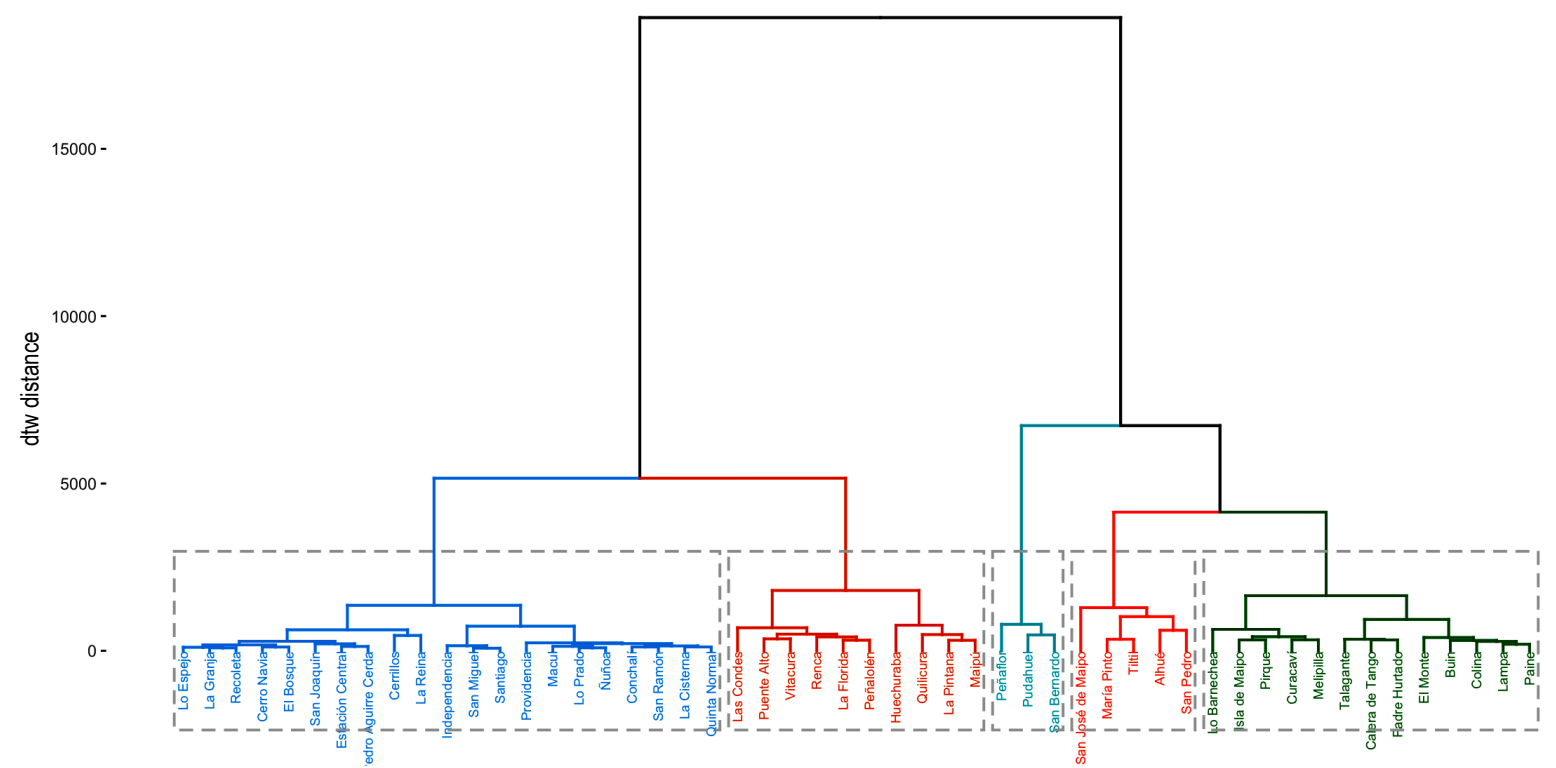

Figure 3. Hierarchical clustering using DTW for mobility time series. The solution with five clusters is highlighted.

The cluster validity indices (CVI) are shown in Table 1 . The solution with two clusters has the best indices. However, basically, this solution indicates that there are communes with low scores (rural communes) and communes with medium/high scores (urban communes). Thus, to consider a more interesting situation, the next best solution is the one corresponding to five clusters.

Figure 4 shows each of the clusters with the time series of their respective members. It is observed that each cluster includes communes with close mobility scores. Thus, Cluster ${ }_{1}$ is made up of the communes with the lowest mobility scores that belong to the approximate score interval (20-40). Cluster $_{2}(40-50)$ and Cluster $_{3}(80-100)$ are made up of the communes with the highest mobility scores. Cluster $_{4}(60-80)$ and Cluster $_{5}(55-65)$ have some overlap. 
Table 1. Cluster validity indices.

\begin{tabular}{cccccccc}
\hline Num. of Clusters & Sil & SF & CH & DB & DBstar & D & COP \\
\hline 2 & 0.8 & 0.0 & 158.6 & 0.2 & 0.2 & 0.1 & 0.1 \\
\hline 3 & 0.6 & 0.0 & 94.0 & 0.2 & 0.3 & 0.1 & 0.1 \\
\hline 4 & 0.7 & 0.0 & 134.1 & 0.3 & 0.4 & 0.1 & 0.1 \\
\hline 5 & 0.7 & 0.0 & 140.6 & 0.3 & 0.3 & 0.1 & 0.0 \\
\hline 6 & 0.6 & 0.0 & 128.5 & 0.3 & 0.4 & 0.1 & 0.0 \\
\hline
\end{tabular}

Sil: Silhouette index [60]; (to be maximized), SF: score function [61] (to be maximized), CH: Calinski-Harabasz index [60] (to be maximized), DB: Davies-Bouldin index [60] (to be minimized), DBstar: Modified DaviesBouldin index (DB*) [62] (to be minimized), D: Dunn index [60] (to be maximized), COP: COP index [60] (to be minimized).
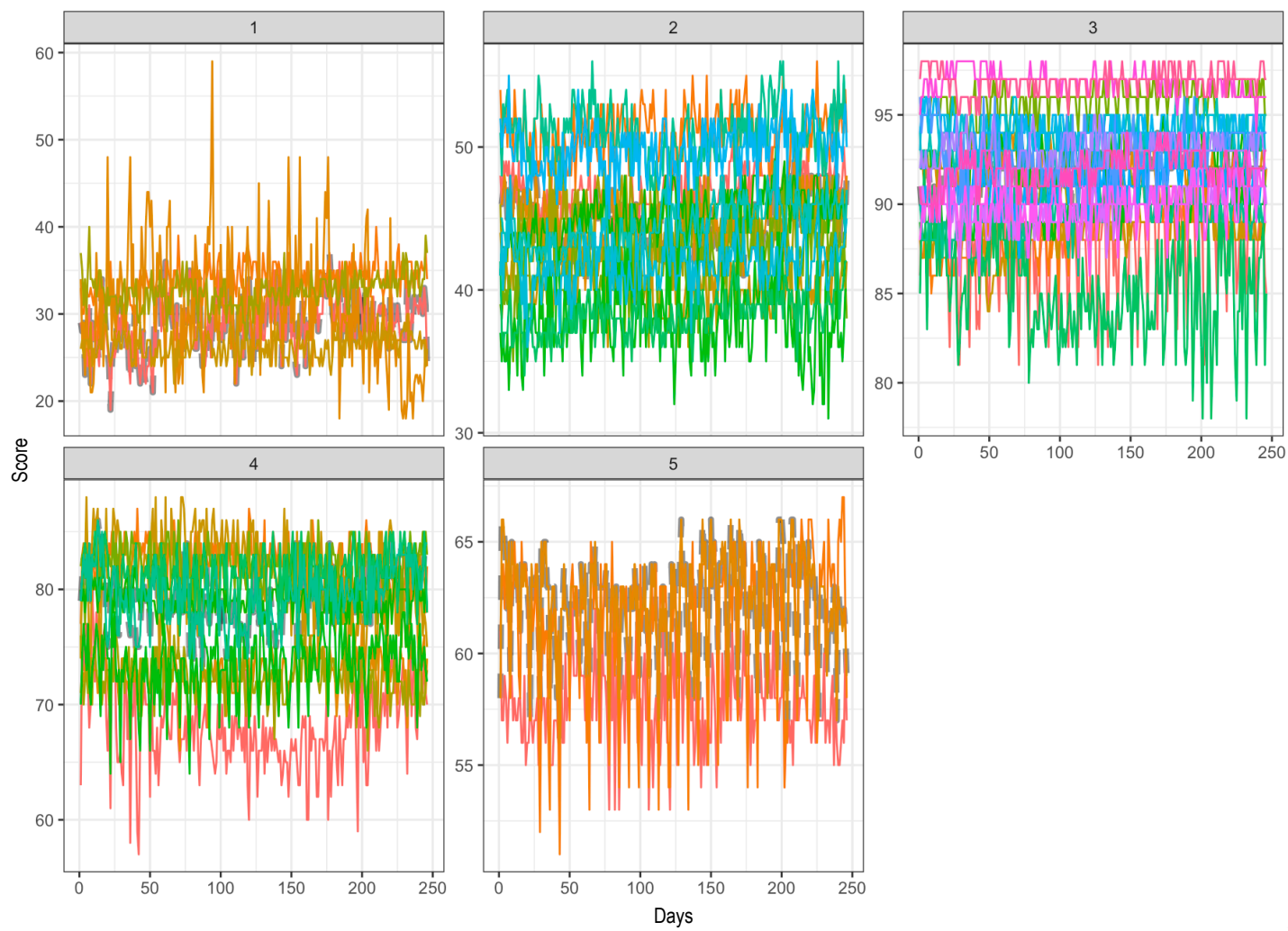

Figure 4. The time series of the commune mobility scores that belong to the five cluster solution. (1) Cluster 1 ; (2) Cluster 2 ; (3) Cluster $_{3}$; (4) Cluster 4 ; (5) Cluster 5.

To better appreciate the value for the analysis of the cluster structure found from the time series of the mobility scores of each commune, Figure 5 shows a sample of 10 communes in the MR and their corresponding membership to a cluster according to their mobility score values.

The two-cluster solution clearly shows that the urban communes (Ñuñoa, Santiago, Estación Central, Vitacura, Puente Alto, and Las Condes) have high mobility scores compared to rural communes (Paine, Pirque, Tiltil and Peñaflor), which have low mobility scores. However, the structure of the cluster shows some more interesting details that this graphic helps to highlight. For example, among the communes belonging to the cluster with low scores, Peñaflor clearly stands out with higher scores. This fact could be explained by the presence of several industries in the area that clearly did not stop operating during the months of the pandemic. 
The central communes of the MR (Santiago, Ñuñoa, and Estación Central) are the ones with the highest mobility scores. This can be explained fundamentally by the population density and/or the large number of services in the area.

An observation of relevance for our subsequent analysis is given by the fact that communes with very dissimilar incomes, such as Las Condes, Vitacura (two of the communes with the highest income in the country), and Puente Alto (a commune with very low income) have very similar mobility scores. Puente Alto is the commune with more COVID-19 cases in the MR, as indicated by the analyzed COVID-19 dataset. However, the communes with the highest income, as mentioned above, have significantly fewer cases. This fact indicates that mobility is not the only factor to consider in the COVID-19 spread. Simply, community-specific infection risk should also reflect other commune attributes that may include income, education, health-care access, and cultural practices, among other possible factors.
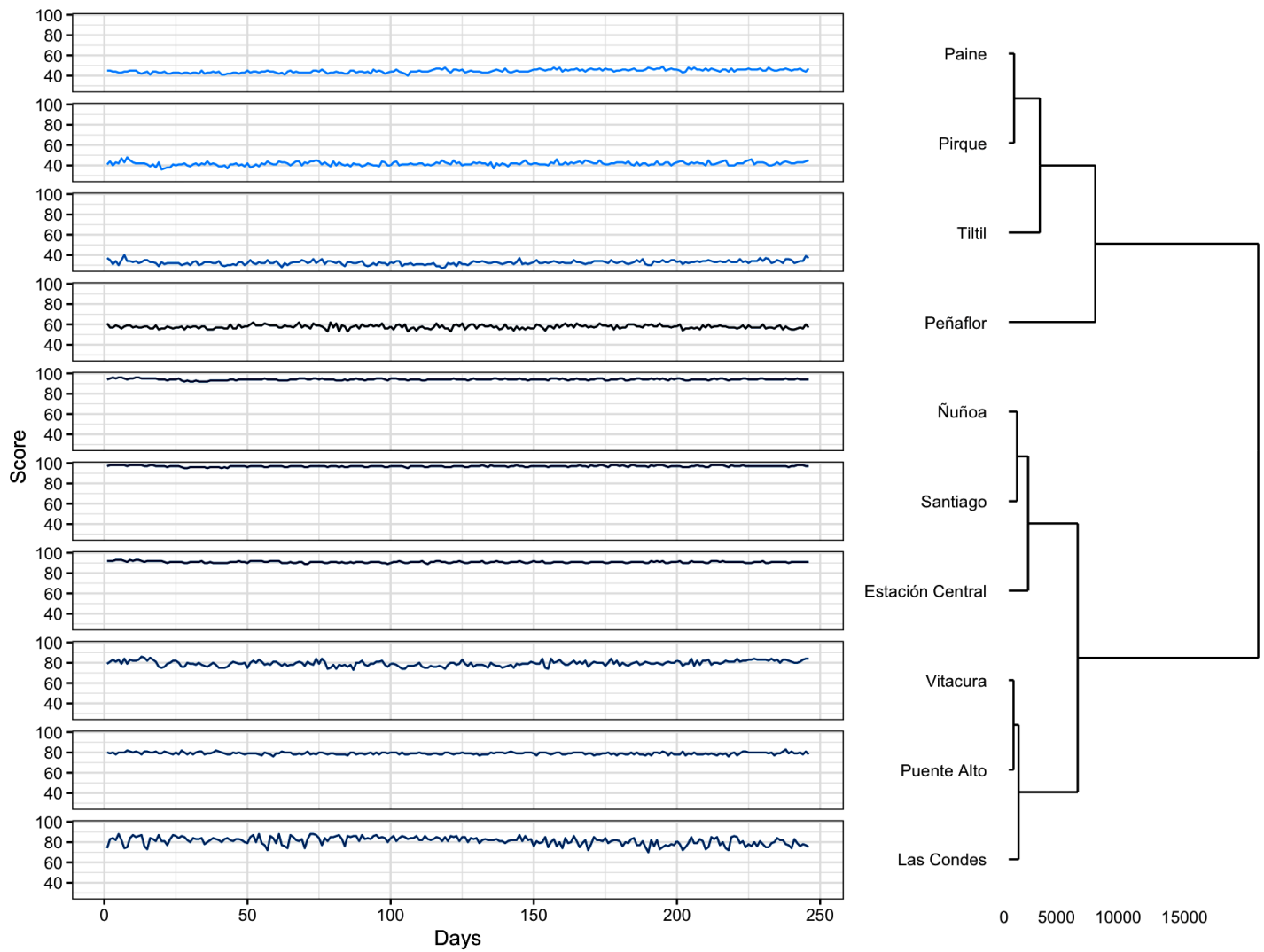

Figure 5. A sample of 10 communes grouped in clusters of similar behavior according to the values of the scores. The central communes of the MR (Nuñoa, Santiago, Estación Central) have the highest scores, while the peripheral rural communes (Paine, Pirque, Tiltil) have the lowest scores. It is also observed that communes with very different incomes may have similar mobility scores (low-income commune: Puente Alto, and high-income communes: VItacura, Las Condes).

From this analysis on mobility scores over time, there emerges a regular pattern. The MR communes belong to specific clusters built with well-defined intervals for the score values. In other words, each commune remains within the same range/interval of percentiles measured from "out-of-home" event distribution across the study period. However, this analysis also tells us that the score, because it only reflects relative changes in mobility between communes, is not very sensitive to capturing the effects of the restriction measures on mobility if they are applied to all MR communes at the same time. 


\subsection{Considering the Impact of Restriction Measures on Mobility by Using the Mobility Index}

The records left by the mobile phones of the users (1.4 million users of the TelefónicaMovistar company) at each antenna when they move inside or to/from the commune are used to build the mobility index of the commune. Using this index as a proxy for human mobility in the commune, we estimated the effects of restriction measures on mobility taken at different dates during the pandemic.

Figure 6 shows the time series for the mobility index in the observation time period from 27 February 2020 to 5 November 2020 for a sample of 16 communes of the MR (the choice of a sample of size 16 is only to obtain a better visualization, and the analysis is done with all the communes of the MR). The figure also includes the dates that correspond to the most important confinement measures taken in this time interval. The numbers in the figure indicate the dates of the main confinement events (details can be found in Appendix A).

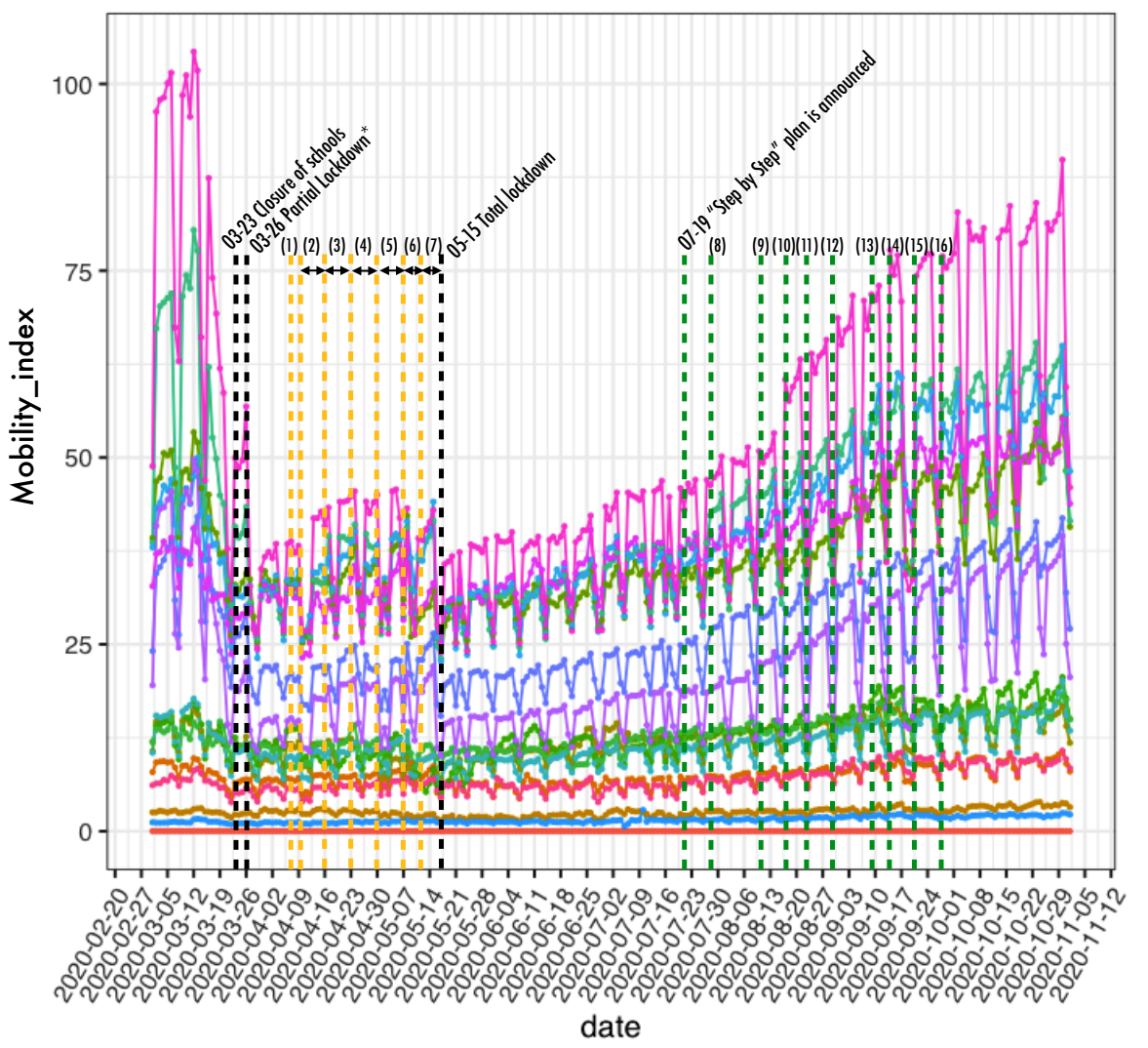

Communes

$\rightarrow$ Alhué

$\rightarrow$ Buin

- Calera de Tango

$\rightarrow$ Independencia

- La Florida

$\rightarrow$ La Granja

- La Pintana

$\rightarrow$ Las Condes

$\rightarrow$ Macul

- Maipú

$\rightarrow$ María Pinto

$\rightarrow$ Ñuñoa

$\rightarrow$ Providencia

$\rightarrow$ Puente Alto

- Santiago

$\because$ Talagante

date

Figure 6. Time series of the mobility index for a sample of 16 MR communes in the period between 27 February 2020 and 5 November 2020. The dates corresponding to the most important confinement measures are highlighted.

The mobility index, as shown in Figure 6, makes it possible to capture the impacts on mobility caused by the application of successive confinement measures and their respective lifting at some later time. It is important to highlight the appreciable effect in the reduction of mobility produced by the closure of schools and later, to a much lesser extent, by the different dynamic quarantines enforced on the communes in the first days of the pandemic.

As of 15 May 2020, a total quarantine was declared for most communes in the MR. In the first days of implementation of this restriction measure, as can be seen in Figure 6, a slight decrease in mobility was recorded in all communes. However, mobility was increasing steadily until reaching the same levels as before the application of quarantine, showing signs of "fatigue" in complying with this restriction measure over time. With the gradual exit of the communes from quarantine, a very abrupt increase in mobility is observed.

Another aspect to highlight is the strong positive correlation found in the mobility index values of all communes of the MR, as is shown in Figure 7. This is a very interesting 
finding and deserves further study; however, it is outside the scope of this work. In practice, this means that communes have very similar and regular patterns of mobility through time, in the sense that if in a particular commune the Mobility index rises or falls steadily, then this index rises or falls steadily in the rest of the other MR communes. This, of course, does not mean that all communes have the same degree of mobility. What it implies is that the temporal evolution of mobility, aggregated at the communal level in a large city such as the MR, reflects very regular and similar patterns over time, which may be dictated by the routine activities of the city (e.g., well-defined travel routes to work during business days, well-established mechanisms in the supply chains).

The effect of this global behavior can also be seen in the analysis of the commune mobility score (see Figure 2). The mobility score describes the relative mobility (percentiles in the score distribution) and shows high regularity and stability throughout the observation time for each commune. This regularity is sustained over time with a few variations and is not affected by confinement interventions. This fact, unlike the mobility index, makes the mobility score of little use, specifically to capture the effect of the confinement policies in the mobility of the MR communes, as was noted at the end of Section 3.1.

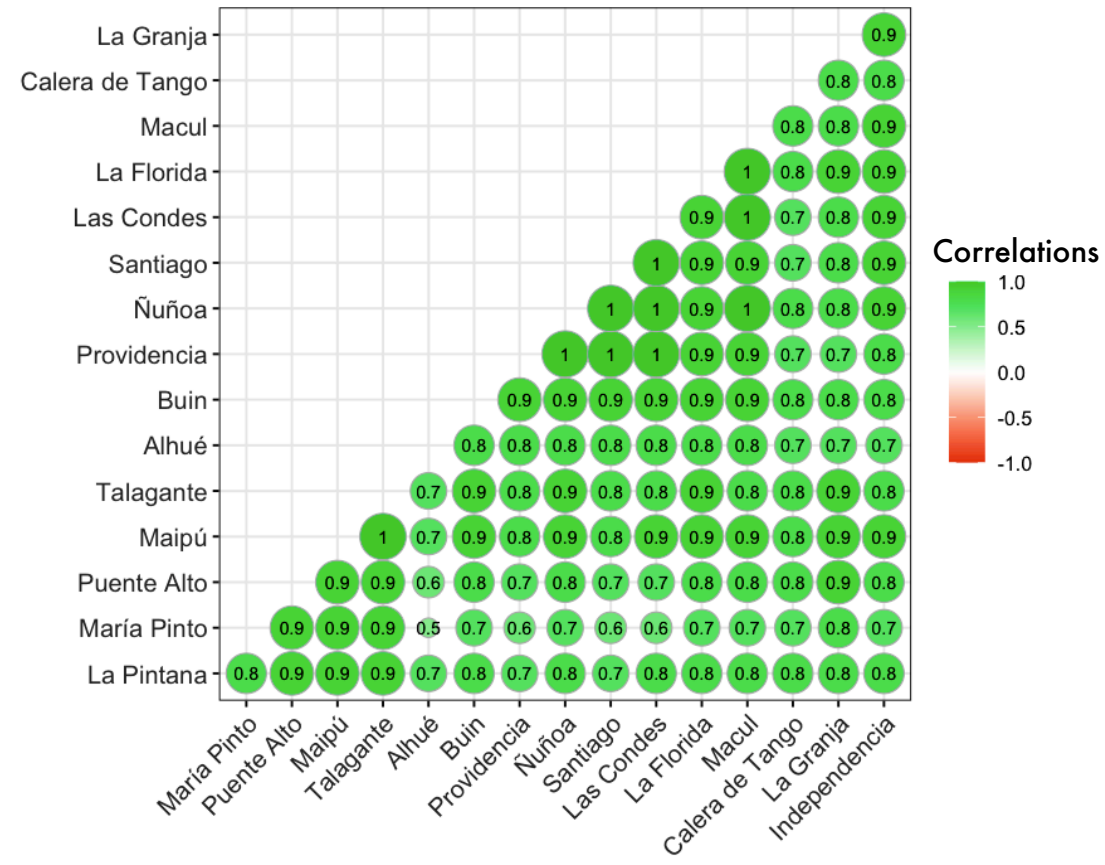

Figure 7. Representation of the correlations between the daily values of the mobility indices for the communes of the Metropolitan Region. A high positive correlation is observed in the mobility of all the communes.

\subsection{Urban Public Transport Seeded the COVID-19 Pandemic across the Santiago} Metropolitan Region

Pre-existing mobility patterns determine the routes along which diseases may potentially spread $[63,64]$. Before the pandemic, like all cities, Santiago MR had its well-defined and regular mobility patterns. These patterns were remarkably well marked in the daily flow of users of the public transport network.

Figure 8 shows the communes of origin and destination connected by the public transport service at two specific times for a given working day of the week. At 6:00 a.m. (panel A), mass exits to workplaces occur, while at 6:00 p.m. (panel B) the return to homes begins. In this figure, the nodes represent the communes (only the urban ones were represented) and the links are the displacements between them.

The thickness of the link between two communes represents the weight, that is, the number of people leaving the commune of departure towards the commune of destination, which is marked by the head of the arrow (directed link). The diameter of the node is 
proportional to the out-degree, which is measured by considering the total weight of the links leaving the node.

The pattern we want to highlight is the massive displacement from the most populated communes (which are also the ones with the lowest incomes) to the communes with the highest income at 6:00 a.m. For example, transportation from communes such as Puente Alto and Maipú to Las Condes and Providencia stands out. Likewise, the opposite effect is shown at 6:00 p.m., the hour at which the return home begins.

During the early days of the pandemic, these are the kinds of patterns that occurred regularly on the working days of the week in the metropolitan public transportation system. It is good to note that due to the so-called social outbreak before the pandemic, displacement patterns were affected. However, these events did not substantially change global trends related to the displacement of workplaces. Even under adverse conditions, people have to go out to work to survive.

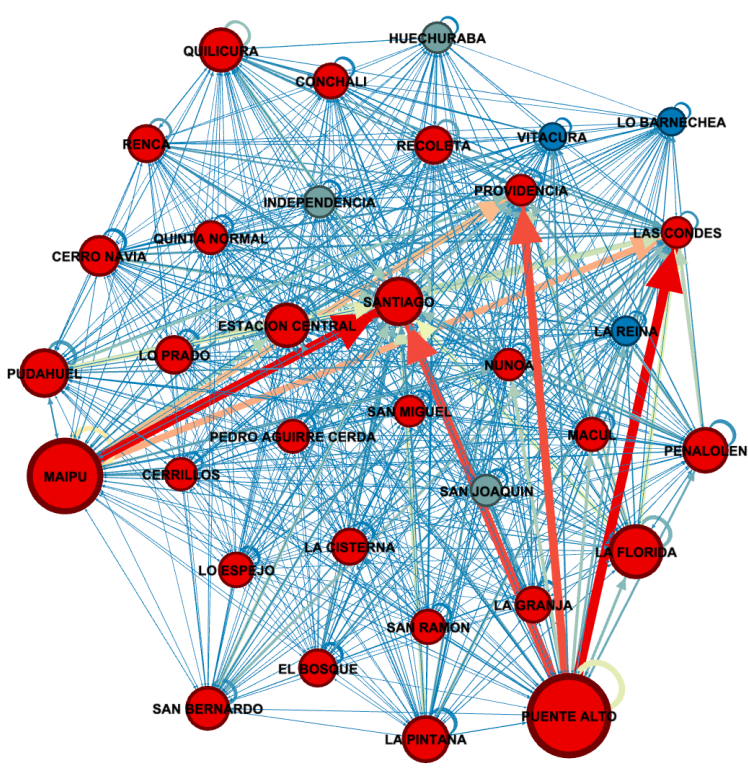

(A)

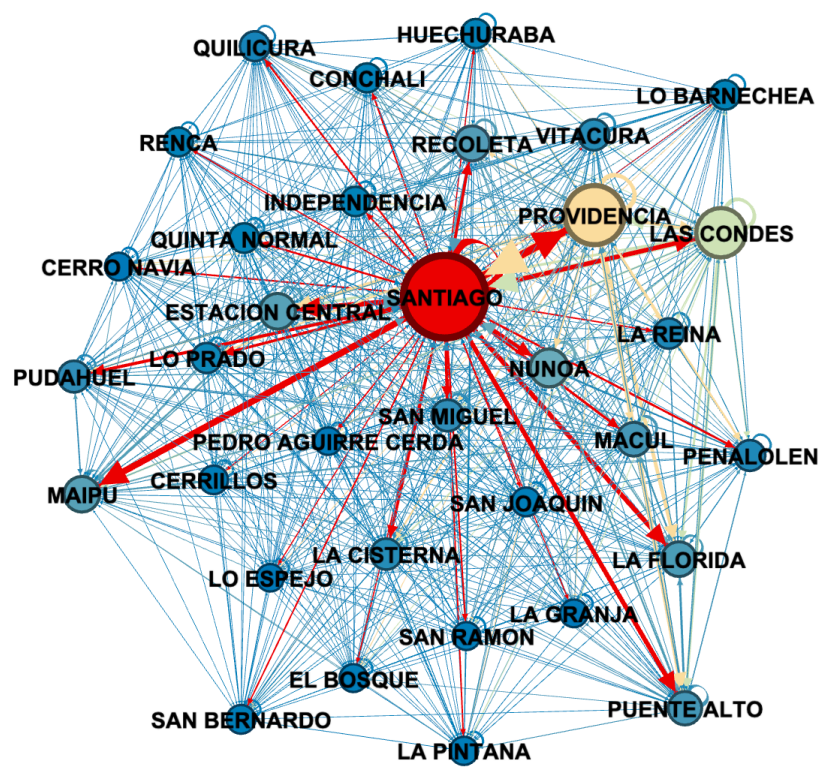

(B)

Figure 8. Origin-destination between communes of Santiago City (A) at 6:00 a.m. and (B) at 6:00 p.m. on a regular pre-pandemic weekday. The sizes of the arrows are related to the number of trips, and the sizes of the nodes with its out-degrees.

The first COVID-19 cases occurred in the MRs richest communes. As of 30 March 2020, among the communes with the highest rate in the whole country were Lo Barnechea 54.8 (68 cases), Las Condes 54.7 (181 cases), and Providencia 52.0 (82 cases), the three communes with the highest per capita income in the country. Taking into account the mobility patterns in public transport (see Figure 8), it could be inferred how the low-income communes may have received the first infections through public transport from the higher-income communes. Moreover, by the time the government authorities decided to partially confine Puente Alto (8 April 2020), the number of cases in this low-income commune had risen to 239 cases (it should be noted that the number of PCRs taken in this commune was low, so the number of actual cases was probably much higher).

Let us take a closer look at these facts in the early days of the pandemic. The first and highest number of infections occurred in the richest communes, while in the poorest communes, the COVID-19 cases were nonexistent or very low.

In this stage, the contagion rate is very high and mobility plays a preponderant role. Although the closure of educational establishments was already in force, this fact did not affect the displacements from the poorest communes to the richest, which are mainly due 
to work reasons. Therefore, we can hypothesize that the spread of contagion is mainly due to the connection, through public transport, to communes that we could call "high-risk communes" due to the high number of infections in them. Consequently, public transport thus becomes the main diffuser of the virus at this stage of the pandemic.

To quantitatively describe this situation, we consider, by using OD matrices, the flow of public transport users from low-income communes to richer communes (with a higher contagion rate). Without any other measure restricting mobility, the flows between communes follow regular and well-established patterns that are observed daily in the public transport of the MR (see Figure 8). Therefore, we estimated the flow between communes by aggregating the number of trips registered with the origin-destination matrices [44]. Only trips between 6:00 a.m. and 8:00 a.m. were considered, as these trips are mainly motivated by work reasons. In the late afternoon, at the end of the working day, mainly from 6:00 p.m., users return to the communes of origin, eventually carrying the virus with them.

To validate the hypothesis, which essentially states that during the first stage of the pandemic the virus spread from the richest to the poorest communes, with a predominant role played by public transport, we built the following regression model:

$$
\begin{aligned}
\text { CumCases }_{i} & =\beta_{1} \cdot \text { Flow }_{i}+\beta_{2} \cdot \text { Flow }_{i} \times \text { MobOut }_{i} \\
& +\beta_{3} \cdot \text { MobOut }_{i}+\beta_{4} \cdot \text { MobIn }_{i}+\beta_{5} \cdot \text { Score }_{i}+\beta_{0}+\epsilon_{i}
\end{aligned}
$$

where Flow $i$ is the the sum of the trips between 6:00 a.m. and 8:00 a.m. from commune $i$ to high-risk communes normalized by the number of inhabitants of commune $i$. We considered the interval from 20 February to 30 March. The variable score ${ }_{i}$ is the average score of commune $i$ in the given time interval. MobIn $i$ and MobOut $_{i}$ are the average internal and external Mobility Indices, respectively, in the indicated interval for commune $i$, and CumCase $i$ are the cumulative cases as of 30 March for commune $i$.

The fit of the regression model (1) is shown in Appendix B. The regression has $R^{2}=0.86$, but we are also interested in the $\beta_{1}$ coefficient, which measures the effect of flows on case growth. This value is positive, and as the statistical test indicates, it is significantly different from zero. This result establishes that a high flow of connectivity between communes with a low number of cases and communes with a high number of cases through public transport produces a quantifiable growth of COVID-19 cases in the former.

A further exploratory data analysis indicates that the low-income communes with the highest regular flow to and from wealthy communes (communes with a high prevalence of COVID-19 in the early stages of the pandemic) later experienced greater growth in the number of cases. This fact, in turn, also suggests that urban public transport was a vector for the spread of contagion in the initial phase of the pandemic. In fact, from the available O-D matrices, it can be shown that from $4 \%$ to $8 \%$ of the population of the MR communes go to work daily to the higher-income communes (Las Condes, Vitacura, Lo Barnechea, and Providencia) using public transport. For communes like Puente Alto, for example, this is more than 25.000 people who move to areas of high risk of contagion and then back. The "interaction" of internal mobility with this flow of users by itself can explain up to $51 \%$ of the variance of the accumulated case data as of March 26 in the MR communes (for this date, the communes: Las Condes, Vitacura, Lo Barnechea, Providencia, Santiago, Nuñoa, Independencia entered into partial lockdown, and a suggested model is: CumCases $_{i}=18.309+4.055 \cdot$ Flow $_{i} \times \operatorname{MobIn}_{i}+\epsilon_{i}$, has $R^{2}=0.51$ ).

As shown in the next section, the clear relationship that model (1) shows between the growth of cases and the mobility indices during the first days of the pandemic is no longer so clear in the subsequent stages. In fact, when confinement measures begin to operate, socioeconomic determinants become more noticeable, and social inequities are more apparent.

\subsection{The Role of Confinement Measures in the Local Evolution of the Pandemic}

Using model (1), we can declare that a significant and quantifiable variation in the number of accumulated cases in a commune is due to the number of trips (flow), for work 
reasons, of a fraction of its inhabitants to the high-risk/high-income communes at the beginning of the pandemic. These trips favored contact with those infected with the virus of the high-income communes. The virus followed established and regular public transport routes to spread to low-income communes.

In the work [65], through counterfactual simulations, the authors showed that taking mobility restriction control measures in a time effective manner reduces the number of infections and deaths. In our study, we show using the available data and model (1) that if these control measures had been implemented earlier, a substantial number of COVID-19 cases could have been prevented, simply because the transmission of viruses to the most precarious communes had been avoided by stopping the flow of public transport users to high-risk/high-income commune. In other words, mobility restrictions could have had a significant impact on reducing the number of cases, but only if the high-risk communes, which in the case of the MR are also high-income communes, are isolated early under strict conditions.

These restrictive measures had to be taken once the virus reached the country and established itself in high-income communities. However, the measures were taken late and could have been not only inefficient but also counterproductive for low-income communes with precarious health and socioeconomic resources [32]. Indeed, the data suggested that restrictions on mobility may even have accelerated the contagion process and thus led to a higher than expected number of cases within low-income communes, as shown in Figure 9.

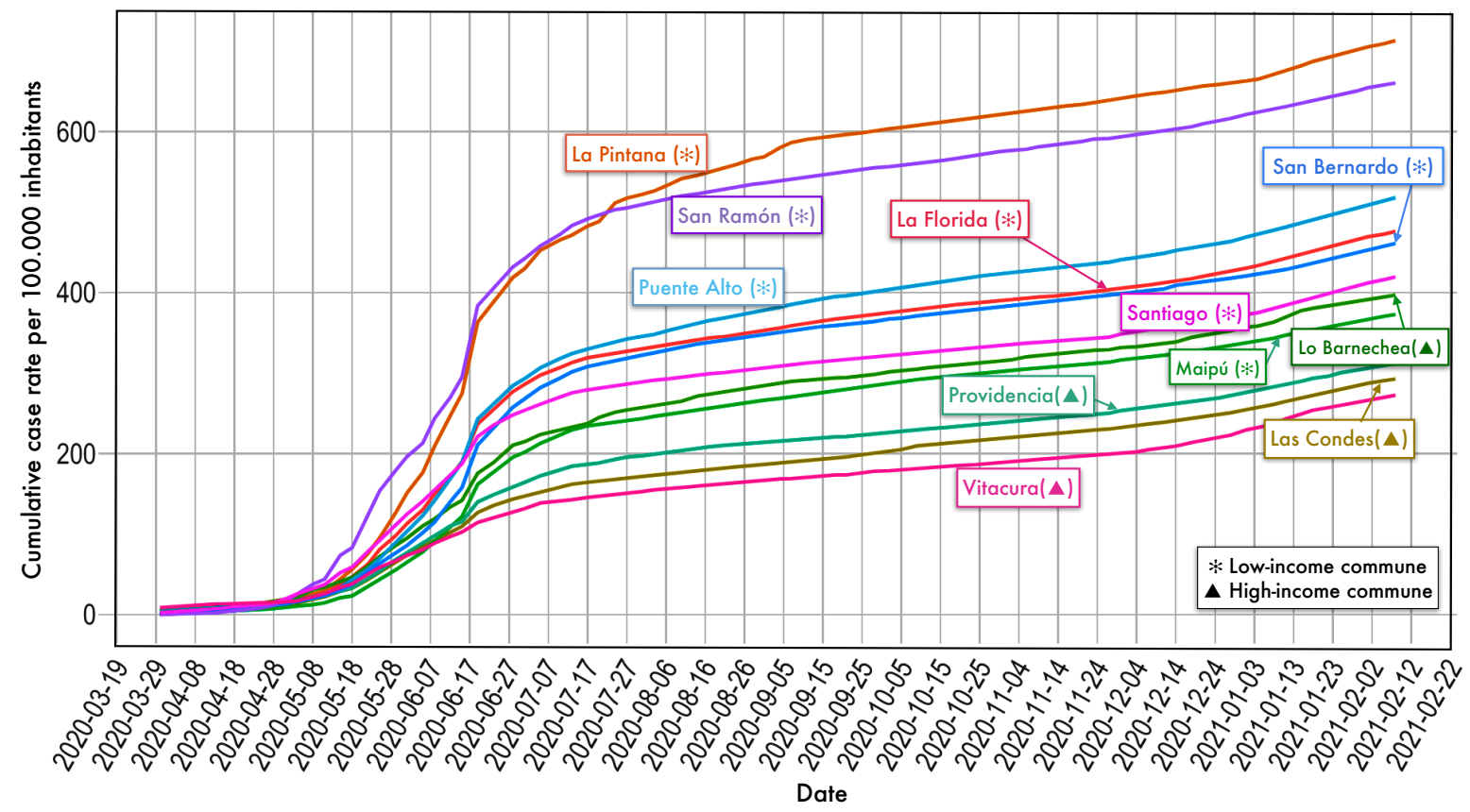

Figure 9. Cumulative cases of COVID-19 for the communes of the Metropolitan Region.

Figure 9 shows the cumulative number of cases per 100.000 inhabitants (that is, $\frac{\text { CumNumber }}{\text { Population }}$ 100.000) from 19 March 2020 to 12 February 2021, for a sample of Santiago MR communes. An explosive growth of COVID-19 cases between April and July is observed. This type of growth is much more sustained and steeper for low-income communes (for example, La Pintana, San Ramón, Puente Alto), marked with (*) in the figure. On the other hand, the high-income communes (for example, Providencia, Vitacura, Las Condes), marked with $(\triangle)$ in the figure, appear to handle the pandemic better since they have fewer cases and gradual contagion rates, as can be seen from the figure.

At this stage (the first days of the mobility restrictions), the internal mobility index $($ MobIn) positively correlates with the number of accumulated cases (correlation $=0.81$ ). While the external mobility index $(\mathrm{MobOut})$ correlates negatively (correlation $=-0.30)$. 
That is, even though the exits/entries to the commune decrease, the number of cases continues to grow with high rates in these communes. However, these correlations change as the constraint measures run their course, as it is shown in Figure 10.

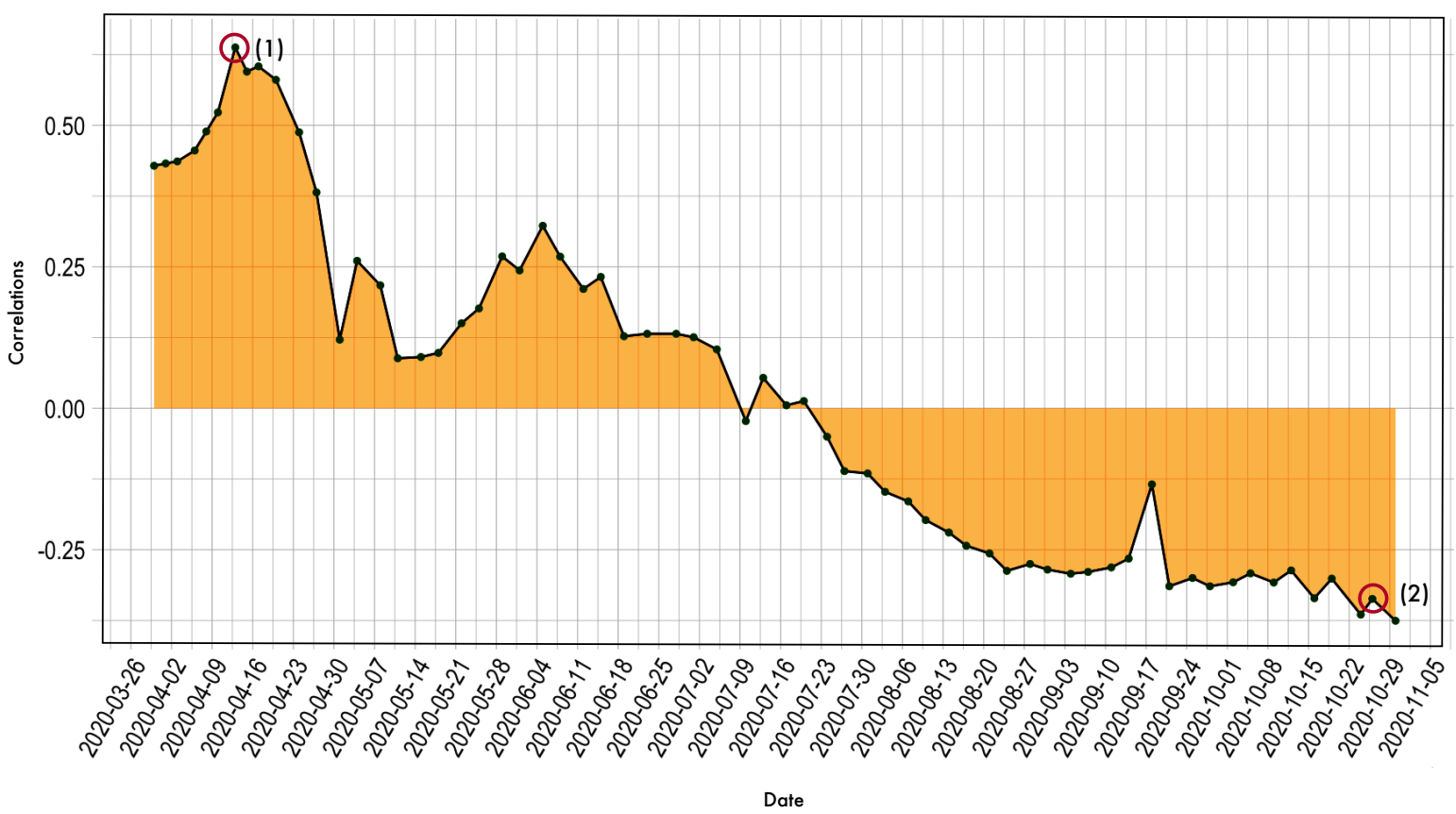

Figure 10. Temporal evolution of the correlation between the mobility index and the cumulative number of COVID-19 cases per 100.000 inhabitants in the period from 26 March to 30 October 2020.

It has been proposed that the most important factor in these adverse effects produced by the confinement measure is that mobility restrictions are not effectively respected. For example, Bennett $\mathrm{M}$. in [66] analyzed the effectiveness of lockdowns at the commune level in Chile during the first two months of the pandemic. She showed that lockdown measures were not effective in lower-income areas that were subject to quarantine at the same time as high-income communes. The cause of this, she explains, is because the mobility restrictions were not respected in the low-income communes. However, a more detailed analysis of the available mobility data shows that other causes may be involved. For example, Figure 6 shows that during the first days of confinement, the effect of restriction measures is appreciable in both poor and rich communes. Furthermore, as shown in Figure 5, the mobilities of poor communes, such as Puente Alto, and that of rich communes, such as Las Condes, are very similar (in the latter being even higher, as shown in Figures 11 and 12 in this section), but the number of cases is very different, disfavoring by far the poorest commune, Puente Alto.

The different socioeconomic conditions of the MR communes and the inequity in resources are manifested at this stage (quarantine) of the pandemic. Mobility stops playing an important role as it is shown by the correlation values between mobility and the number of COVID-19 cases in Figure 10, which is practically null for this period.

In fact, in the first stage of the pandemic, there is a strong positive correlation between mobility, measured by the mobility index, and the number of COVID-19 cases, but as of 26 March, the partial and dynamic quarantines begin and this clear correlation begins to fade off.

Figure 10 shows the correlation between the mobility index and the cumulative number of cases per 100.000 inhabitants of the commune. This correlation is calculated for the period of time that goes from 26 March to 30 October 2020. Two dates, in particular, are marked in the figure: 17 April with a maximum positive correlation (0.6) and 26 October with a negative correlation $(-0.34)$. 
On 26 March, it is still observed that the communes with higher incomes and also with greater mobility have a greater number of cases (high-risk communes). Although other determinants should be considered, in addition to mobility, a regression model indicates that mobility alone explains about $37 \%$ in the variability of the observed cases $\left(R^{2} \approx 0.37\right)$ in this phase of the pandemic. Figure 11 shows a scatter diagram in which the horizontal axis stands for the mobility index and the vertical represents the cumulative number of COVID-19 cases per 100.000 inhabitants. The radius of the bubbles is proportional to the population in each commune.

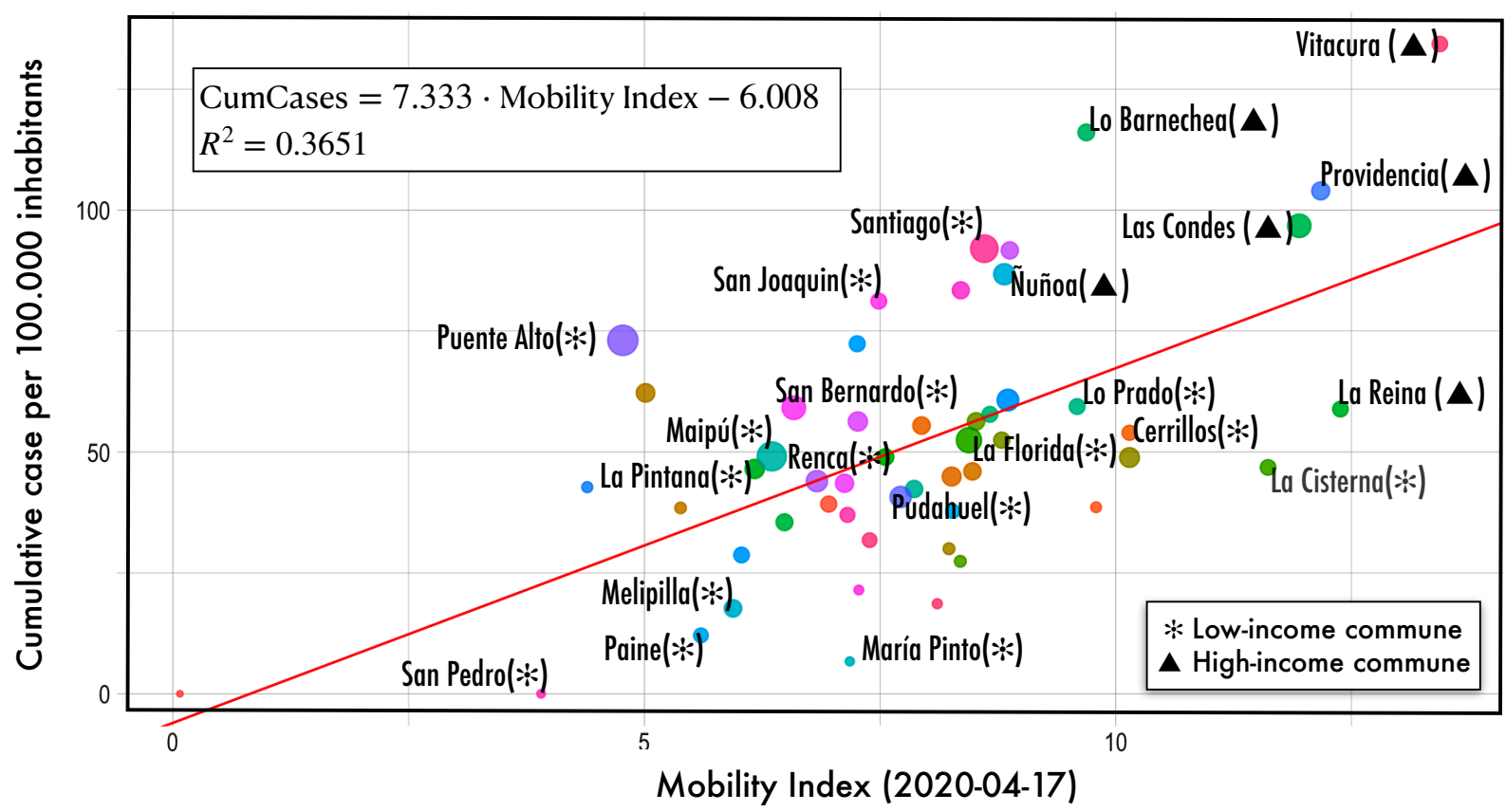

Figure 11. Mobility index vs. cumulative number of cases per 100.000 inhabitants of the commune at the beginning of the total quarantine for the communes of the Metropolitan Region. The radii of the bubbles are proportional to the commune population.

A characteristic pattern of this stage of the pandemic is observed. High-income communes have high mobility and a high number of cases, which makes them particularly active in spreading the virus. It could be inferred that total and effective isolation of these communes in the early stages of the pandemic would have significantly reduced the magnitude of the contagion. On the other hand, more towards the center of the figure and above, with less mobility and with a smaller but already significant number of cases, are the low-income communes. Further down and to the left are rural communes characterized by low mobility and a low number of cases.

As of 15 May, the total quarantine comes into effect. However, by this date, the contagion has spread to the lowest-income communes, and the measure seems to be enforced late for these communes. Although there is still a positive correlation between mobility and the number of cases, this correlation is becoming smaller and smaller. There is a slight decrease in mobility at the beginning of this period, but it never decreased significantly, as was shown in Figure 6, which indicates a slow but sustained growth in mobility for this period.

By October, the situation has changed. Mobility has been increasing and the communes with the highest incomes have the highest values in the mobility index, while the number of cases in these communes is low. Figure 12 shows a scatter diagram illustrating this stage of the pandemic. Again, clear patterns can be seen in the distribution of the communes in the figure. On the bottom right, with high mobility and a low number of cases are the communes with the highest income. In the center, with less mobility but with a much 
higher number of cases, are the low-income communes. Further to the left and below, preserving a situation similar to that shown in Figure 11, the rural communes are located. In this period, mobility is a variable that explains only $11 \%$ of the variance of the observed cases $\left(R^{2} \approx 0.11\right)$ and obviously, other determinants, such as socioeconomic conditions and vulnerability in general, are fundamental to explaining the observed contagion patterns.

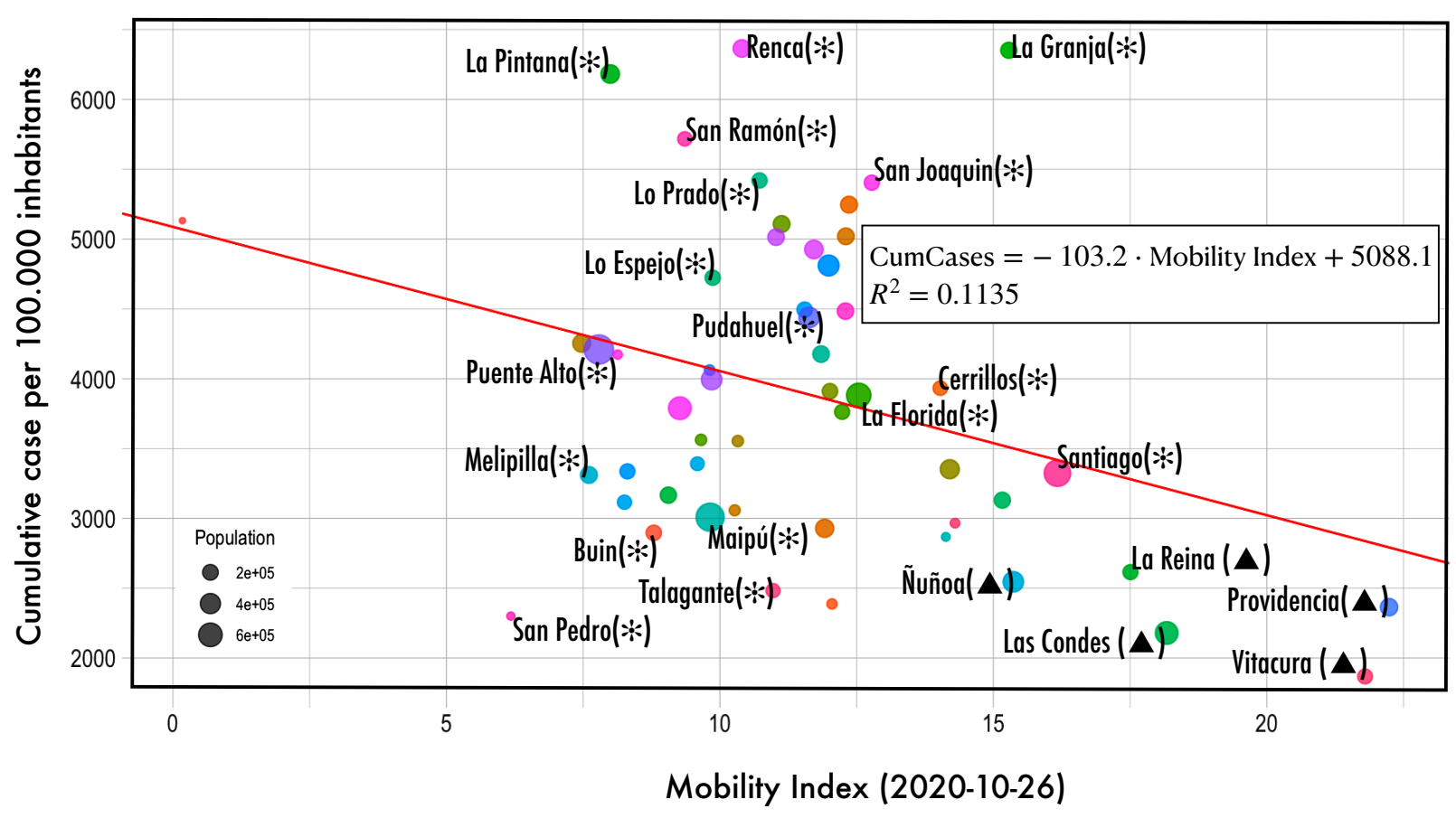

Figure 12. The mobility index vs. the cumulative number of cases per 100.000 inhabitants after relaxing the confinement measures.

The sustained increase in mobility, once control measures are relaxed or eliminated, in locations with sustained transmission can reintroduce infections in places where transmission is well suppressed, increasing the opportunities for local transmission and case growth, triggering a second regrowth or "second wave". The first signs of this situation can already be seen in Figure 9 where the cumulative case curves since the end of December begin to show an increase in the growth rates of COVID-19 cases.

\subsection{Assessment of the Timely Lifting of Quarantine Measures through Augmented Synthetic Control Method}

Another relevant aspect of the analysis of the role of mobility restriction measures is precisely the timely lifting of these measures, especially quarantine. Since 15 May 2020, a long period of quarantine has been implemented in the MR. Although the measure was taken for practically all the communes of the MR simultaneously, the de-confinement occurred gradually. The communes were coming out of quarantine as the number of cases decreased. The first to leave were Colina, La Reina, Las Condes, Lo Barnechea, Til Til, and Vitacura (basically some rural communes, along with the communes with the highest income). On the other hand, the communes with the longest confinement time are at a partial level: Puente Alto, specifically the western sector, which was under the measure for 172 days; and in their territorial totality: El Bosque and Quinta Normal, where quarantines were in force for 158 days (all these communes are low-income). The case of Puente Alto is particularly interesting, given that it is the commune with the most COVID-19 cases in the country and where the lockdown measures were, therefore, inefficient.

We used synthetic control [67] to estimate the effect that the lifting of the quarantine had on the number of cases and also on the mobility of the affected communes. For the 
analysis, we consider that the communes in the "pre-treatment" stage are all those that are in quarantine (practically all the communes of the MR for the observation time interval considered).

In this case, the "treatment" is lifting the quarantine, which the communes were gradually leaving. To consider this staggered lifting of the confinement measures and to be able to estimate the "treatment effects", we used the augmented synthetic control method (ASCM) [67-69]. The objective here is to estimate its consequences on mobility and the number of COVID-19 cases for these communes by comparing with the opposite option, that is, having spent more days in quarantine.

The idea is to construct a weighted average of donor communes, known as a synthetic control, that matches the pre-treatment results of the treated communes. The estimated effect is then the difference in post-treatment outcomes between the treated communes and the synthetic control. The donors for the estimation were determined from the available group of communes and their memberships to different clusters previously defined from the similarities in mobility and also considering the socioeconomic conditions of the communes.

Figure 13 shows the estimate of the effect of lifting the quarantine in the Recoleta, San Ramón, La Cisterna, La Granja, San Joaquín, and San Miguel communes (all of them with low income) compared to the synthetic control built from other communes with similar socioeconomic characteristics that subsequently abandoned the quarantine (Quinta Normal, La Pintana, Lo Prado, Cerro Navia, Conchalí, Puente Alto and Lo Espejo). The figure describes how, initially, the number of COVID-19 cases, on average, for the treated communes tends to fall after lifting the restriction measure. However, this number is rapidly growing again, indicating that the measure may have caused a resurgence of contagion in the treated communes.

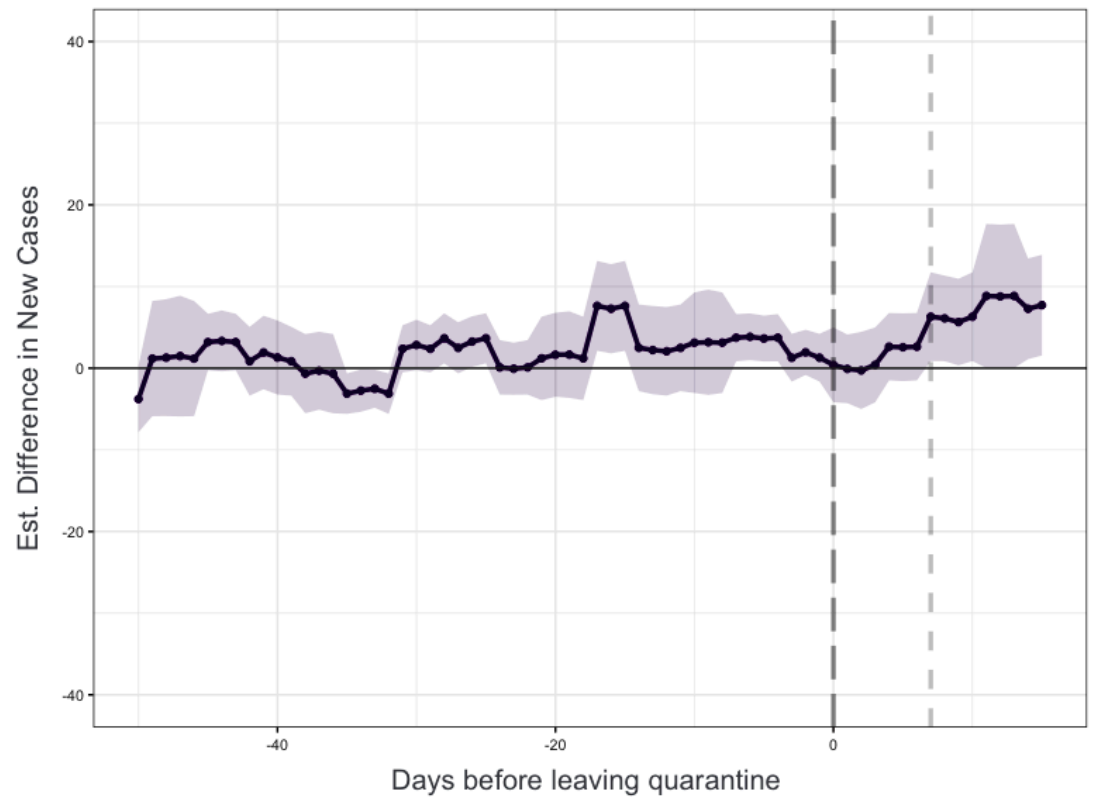

Figure 13. Estimation of the effect of lifting the quarantine on COVID-19 new cases for low-income communes in the Metropolitan Region.

On the other hand, Figure 14 shows the gradual increase in mobility after relaxing the confinement measure. Because the lifting of the quarantine was not total and the communes went to the so-called Phase 2 of the "Step by Step" plan (i.e., the quarantine measure was maintained only on weekends), periodicity is observed in the estimation of the mobility difference. On weekends, the difference with the mobility of the synthetic control decreases as, once again, the communes are temporarily quarantined. 


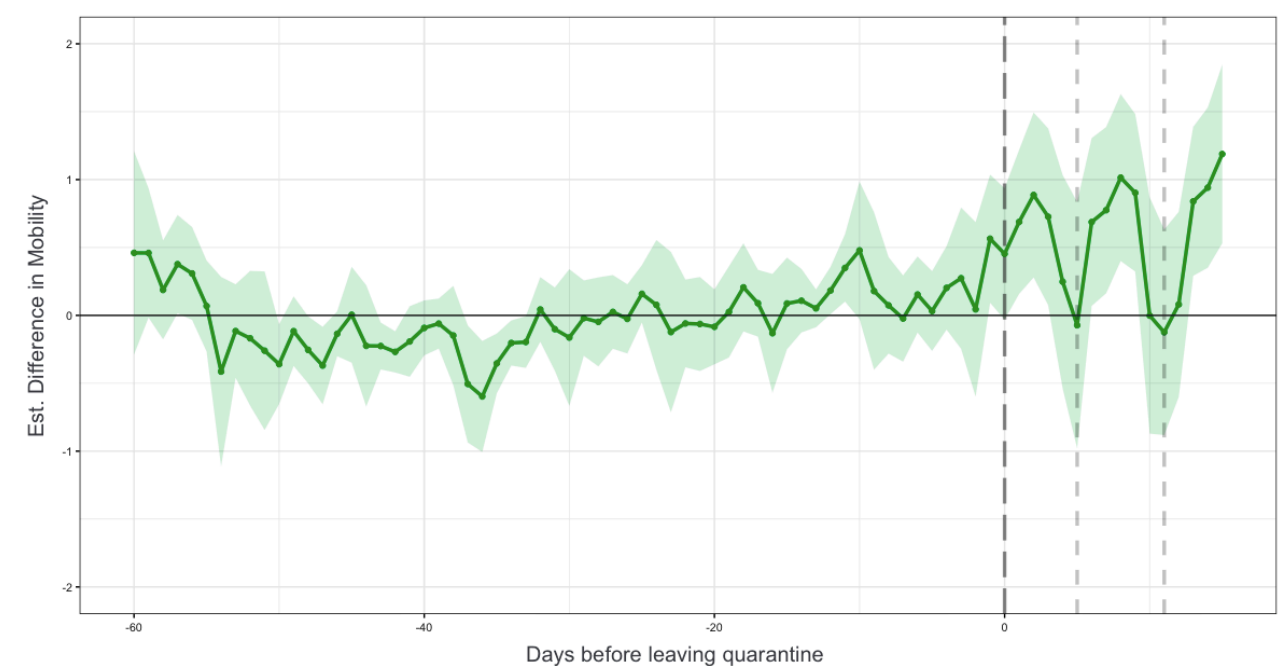

Figure 14. Estimation of the effect of lifting the quarantine on mobility in low-income communes of the Metropolitan Region.

\section{Conclusions}

Although there is a vast and growing literature that analyzes the evolution of the pandemic, there are still numerous unknowns related to local contexts, the routes of spread, and the precise time of application of the restriction measures, among many other topics that are not yet clear. In this work, we used a data-driven approach, taking advantage of the detailed data recorded during the pandemic, to address the complex context of the spread of COVID-19.

The main contribution of this work lies in using the data to show how different forces intervene in shaping the spread patterns of the virus. We find, for example, that mobility is more correlated with the number of cases during the first part of the pandemic, precisely when there is an exponential growth in the number of cases. When the quarantine measures come into effect, this correlation becomes very low or practically null, allowing other factors to have a greater preponderance, for example, socioeconomic factors, which explain the sustained increase in the number of cases despite a decrease in mobility.

The precise moment to implement the restriction measures is also addressed in this work, as well as the propagation routes given by the use of public transport, which led to the spread of the virus from high-income to low-income communes in the first stage of the pandemic. This study also highlights that the restriction measures were successful in high-income communes; however, their effect was very limited in low-income communes, repeating patterns similar to those that have occurred in other parts of the world.

Furthermore, the precise time to withdraw the restriction measures is also addressed in the paper, demonstrating that in the poorest communes, the lifting of the measures was done at the wrong time, causing subsequent growth in the number of cases once the measure was lifted.

Some limitations: This work did not address in detail which socioeconomic factors are the most influential in diffusion, and this analysis is for future work. The data used includes only the year 2020. However, new phenomena have emerged with the application of vaccines, the appearance of new variants of the virus, clear signs of fatigue in the population that is unwilling to serve long periods of confinement, etc., in the current year of 2021. These analyses are also left for future work.

\section{Discussion}

One of the objectives of this work was to make a consistent and validated narrative with the available data on the contagion patterns observed during the evolution of the pandemic in the MR of Santiago. This description of the events would help to understand 
how several interacting causes shape the observed patterns of the virus spread and would support decision-making in future contagion developments.

The available data comprise (1) human mobility data, (2) socioeconomic data, and (3) COVID-19 epidemiological data. The used methodology was based on: (1) discovering/analyzing mobility patterns; (2) analysis of correlations and regression models; and (3) generating synthetic data to estimate causal relationships in the number of COVID-19 new cases and the mobility after lifting the mobility restriction measures.

The initial contagion in the MR of Santiago begins in the richest communes where its inhabitants can afford international travel. Therefore, at the beginning of the pandemic, these communes were at high risk of contagion. An effective containment measure at this stage (creating a sanitary cordon around high-risk communes) could have reduced the size of the subsequent contagion across the country. This measure was not taken in time, and the virus followed established routes of human mobility to spread. This occurs mainly through the public transport service. In fact, workers who have their source of work in high-risk communes were infected and carried the virus with them to their communes of origin. The effect is a rapid spread in both rich and low/middle-income communes, reinforced by the fact that workers use public transport to travel between communes.

At this stage, there is a strong correlation between mobility and the number of cumulative cases of COVID-19 in each commune. Thus, the government begins with the policies of confinement and quarantines. The measure has a positive effect in the richest communes, which have greater resources and a better socioeconomic situation, but in the low/middle-income communes, its effectiveness is poor, and there are even cases of an acceleration in the number of cases for these communes. In most cases, far from a decrease, the reverse effect is observed.

There is no appreciable decrease in the internal mobility of the communes, but this happens similarly for both poor and rich communes. In low-income communes, it is impossible to stay home due to the lack of food and financial resources to survive in combination with little and late government aid. The effects are aggravated by the reduction in the number of services (in addition to its high geographic concentration that produces long lines and crowds of people), and the confinement measures prevent people from "escaping" from the high-incidence places.

As a result, the contagion and the number of deaths grew in low-income communes, despite quarantines and measures taken. This entire situation is aggravated by poor hygienic conditions, frequent base diseases in the population, and poor diet, among other factors that further promote the spread and mortality of the virus.

After a long time with the conditions described above, that is, high rates of infection and death, finally, the confinement measures begin to work and the number of cases begins to decrease. From here, the government begins to gradually relax the measures of restriction of mobility, and slowly several communes leave the quarantine.

However, the virus remains in the population, mainly in some "pockets" located in low-income communes. With the explosive increase in mobility and the return to the old routes of movement, the conditions are again in place for the virus to spread again, thus beginning what some have called the "second wave". From here on, the government again takes up lockdown policies, this time through the "Step by Step" plan. However, restrictive measures lose their effectiveness. The long period lived with restrictions gives way to clear elements of "fatigue". On the one hand, people lose respect for these measures, and on the other, they simply do not have the economic resources to comply with them. Eventually, this creates the conditions for this second wave to have greater proportions or for a high prevalence level to be maintained for a long period of time in which the number of cases cannot be reduced.

Author Contributions: Investigation, M.H. and A.G.-F. All authors have read and agreed to the published version of the manuscript.

Funding: This research received no external funding. 
Data Availability Statement: Not Applicable, the study does not report any data.

Acknowledgments: We thank the United Nations Development Program UNDP-GRANDATA for providing part of the data used in this work in the context of the UNDP LAC call for research proposals "Exploring impact and response to the COVID-19 pandemic in Latin America and the Caribbean using mobility data". We also thank Project ANID/FONDAP/15130015.

Conflicts of Interest: The authors declare no conflict of interest.
Abbreviations
The following abbreviations are used in this manuscript:
MR Metropolitan Region of Santiago de Chile
DTW Dynamic Time Warping
CVI Cluster Validity Indices
PCR Polymerase Chain Reaction
ASCM Augmented Synthetic Control Method

\section{Appendix A. Timeline of Major Events Related to Confinement Measures for Communes in the Metropolitan Region of Santiago from 26 March 2020 to 28 September 2020}

(*) 03/26-02/04 Las Condes, Vitacura, Lo Barnechea, Providencia, Santiago, Ñuñoa, Independencia enter into partial lockdown.

(1) 02/04-08/04 Independence comes out of quarantine.

(2) 04/09-04/16 Las Condes, Santiago (North), Ñuñoa (North), remain in quarantine. Puente Alto (West) enter into partial lockdown.

(3) 04/16-04/23 Only Santiago (North), Ñunoa (North), El Bosque,

San Bernardo (Northeast) remain in quarantine.

(4) 04/23-04/30 Santiago (North), Ñunoa (North), Quinta Normal, PAC,

El Bosque, San Bernardo (Northeast), Puente Alto (West)

in partial lockdown.

(5) 04/30-05/07 Santiago (North), Ñuño (North), Quinta Normal, Estación Central, PAC, Independencia, El Bosque,

San Bernardo (Northeast), Puente Alto (West), San Ramón (South)

in partial lockdown.

(6) 05/07-05/12 Santiago, Quilicura, Recoleta, Independencia, Quinta Normal, Ñuñoa (North), Estación Central, Cerrillos, PAC, San Ramón (South), San Bernardo (Northeast), Puente Alto (West) in partial lockdown.

(7) 05/12-05/15 Total Lock-down for: Santiago, Quilicura, Conchalí, Cerro Navia, Renca, Recoleta, Independencia, Quinta Normal, Macul, Lo Espejo, San Miguel, San Joaquín, Peñalolén, La Florida, La Granja, La Cisterna, La Pintana, Estación Central, Cerrillos, PAC, San Ramón, San Bernardo (Northeast), Puente Alto (West)

(8) $07 / 28$ The first communes go to phase 2, transition $\backslash$ cite\{paso-paso\}:

Colina, La Reina, Las Condes, Lo Barnechea, Til Til, Vitacura.

(9) $08 / 10$ Lampa, Melipilla y Providencia go to phase 2, transition.

(10) $08 / 17$ Santiago y Estación Central go to phase 2, transition.

(11) 08/24 San José de Maipo, Peñalolén, Padre Hurtado y Peñaflor

go to phase 2 , transition. Paine enters quarantine.

(12) 08/31 La Florida, Maipú, Cerrillos, Calera de Tango, El Monte, PAC,

Macul, Talagante y Huechuraba go to phase 2, transition.

(13) 09/07 Recoleta, San Ramón, La Cisterna, La Granja, San Joaquín

y San Miguel go to phase 2, transition.

(14) 09/14 Quilicura, Isla de Maipo, San Bernardo go to phase 2, transition.

(15) $09 / 21$

Pudahuel, Independencia y El Bosque go to phase 2, transition

(16) $09 / 28$

Quinta Normal, La Pintana, Lo Prado, Cerro Navia, Buin, Conchalí, 
Puente Alto, Lo Espejo go to phase 2, transition.

For an explanation of the meaning of phase 2 transition, see [40].

\section{Appendix B. Regression Coefficients}

Coefficients:

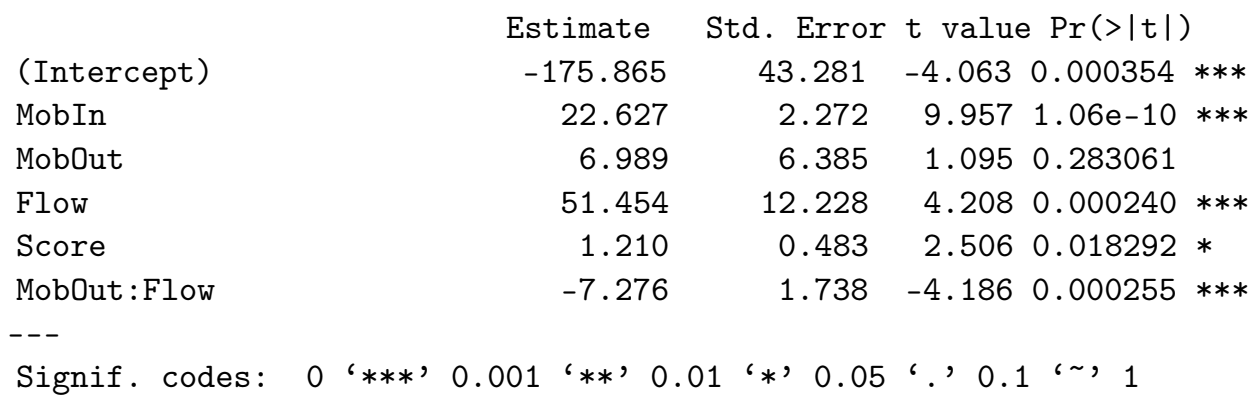

Residual standard error: 25.67 on 28 degrees of freedom

Multiple R-squared: 0.8574 ,Adjusted R-squared: 0.832

F-statistic: 33.68 on 5 and 28 DF, p-value: 5.178 - 11

\section{References}

1. Chang, S.; Pierson, E.; Koh, P.W. Mobility network models of COVID-19 explain inequities and inform reopening. Nature 2021, 589, 82-87. [CrossRef] [PubMed]

2. Hackl, J.; Dubernet, T. Epidemic Spreading in Urban Areas Using Agent-Based Transportation Models. Future Internet 2019, 11, 92. [CrossRef]

3. Dorn, A.V.; Cooney, R.E.; Sabin, M.L. COVID-19 exacerbating inequalities in the US. Lancet 2020, 395, 1243-1244. [CrossRef]

4. Badr, H.S. Association between mobility patterns and COVID-19 transmission in the USA: A mathematical modelling study. Lancet Infect. Dis. 2020, 20, 1247-1254. [CrossRef]

5. Chu, I.Y.-H.; Prima, A.; Heidi, J.L.; Leesa, L. Social consequences of mass quarantine during epidemics: A systematic review with implications for the COVID-19 response. J. Travel Med. 2020, 27, taaa192. [CrossRef]

6. Kraemer, M.U.G. The effect of human mobility and control measures on the COVID-19 epidemic in China. Science 2020, 368, 493-497. [CrossRef]

7. Buckee, C.O. Aggregated mobility data could help fight COVID-19. Science 2020, 368, 145-146. [CrossRef]

8. Glaeser, E.L.; Gorback, C.S.; Redding, S.J. How Much does COVID-19 Increase with Mobility? Evidence from New York and Four Other U.S. Cities; Working Paper 27519; National Bureau of Economic Research: Cambridge, MA, USA, 2020.

9. Engle, S.; Stromme, J.; Zhou, A. Staying at Home: Mobility Effects of COVID-19. Available online: https://voxeu.org/article/ staying-home-mobility-effects-covid-19 (accessed on 26 April 2021).

10. Bajardi, P.; Poletto, C.; Ramasco, J.J.; Tizzoni, M.; Colizza, V.; Vespignani, A. Human mobility networks, travel restrictions, and the global spread of 2009 H1N1 pandemic. PLoS ONE 2011, 6, e16591. [CrossRef]

11. Zhang, C.; Qian, L.X.; Hu, J.Q. COVID-19 Pandemic with Human Mobility Across Countries. J. Oper. Res. Soc. China 2020. [CrossRef]

12. Grantz, K.H.; Meredith, H.R.; Cummings, D.A.T. The use of mobile phone data to inform analysis of COVID-19 pandemic epidemiology. Nat. Commun. 2020, 11, 4961. [CrossRef]

13. Gozzi, N.; Tizzoni, M.; Chinazzi, M.; Ferres, L.; Vespignani, A.; Perra, N. Estimating the effect of social inequalities in the mitigation of COVID-19 across communities in Santiago de Chile. medRxiv 2020, 8, 20204750. [CrossRef]

14. Tatem, A.J. Integrating rapid risk mapping and mobile phone call record data for strategic malaria elimination planning. Malar. J. 2014, 13, 52. [CrossRef] [PubMed]

15. Peak, C.M. Population mobility reductions associated with travel restrictions during the Ebola epidemic in Sierra Leone: Use of mobile phone data. Int. J. Epidemiol. 2018, 47, 1562-1570. [CrossRef] [PubMed]

16. Oliver, N. Mobile phone data for informing public health actions across the COVID-19 pandemic life cycle. Sci. Adv. 2020, 6, eabc0764. [CrossRef] [PubMed]

17. Pollina, E.; Busvine, D. European mobile operators share data for coronavirus fight. Reuters 2020, 37, 1.

18. Blondel, V.D.; Decuyper, A.; Krings, G. A survey of results on mobile phone datasets analysis. EPJ Data Sci. 2015, 4, 10. [CrossRef]

19. Kimberley, C.; Haosheng, H.; Horn, C.; Kasanicky, I.; Weibel, R. Inferring fine-grained transport modes from mobile phone cellular signaling data. Comput. Environ. Urban Syst. 2019, 77, 101348. [CrossRef] 
20. Bachir, D.; Khodabandelou, G.; Gauthier, V.; El Yacoubi, M.; Puchinger, J. Inferring dynamic origin-destination flows by transport mode using mobile phone data. Transport. Res. Part C Emerg. Technol. 2019, 101, 254-275. [CrossRef]

21. Silm, S.; Järv, O.; Masso, A. Tracing human mobilities through mobile phones. In Handbook of Research Methods and Applications for Mobilities; Büschner, M., Freudendal-Pedersen, M., Kesselring, S., Kristensen, N.G., Eds.; Edward Elgar Publishing: Cheltenham, UK, 2020; pp. 303-323.

22. Anderson, R.M.; Heesterbeek, H.; Klinkenberg, D.; Hollingsworth, T.D. How will country-based mitigation measures influence the course of the COVID-19 epidemic? Lancet 2020, 395, 931-934. [CrossRef]

23. Chinazzi, M. The effect of travel restrictions on the spread of the 2019 novel coronavirus (COVID-19) outbreak. Science 2020, 368, 395-400. [CrossRef]

24. Dehning, J.; Zierenberg, J.; Spitzner, F.P.; Wibral, M.J.; Pinheiro, J.; Wilczek, M.; Priesemann, V. Inferring change points in the spread of COVID-19 reveals the effectiveness of interventions. Science 2020. [CrossRef]

25. Eichner, M.; Schwehm, M.; Wilson, N.; Baker, M.G. Small Islands and Pandemic Influenza: Potential Benefits and Limitations of Travel Volume Reduction as a Border Control Measure. BMC Infect. Dis. 2009. [CrossRef]

26. Ullah, A.; Ajala, O.A. Do lock-downs and testing help in curving COVID-19 transmission? COVID Economics. CEPR 2020, 13, 138-156.

27. Cetron, M.; Landwirth, J. Public health and ethical considerations in planning for quarantine. Yale J. Biol. Med. 2005, 78, 329. [PubMed]

28. Onishi, N. As Ebola Grips Liberia's Capital, a Quarantine Sows Social Chaos. Available online: https:/ / www.nytimes.com/2014 /08/29/world/africa/in-liberias-capital-an-ebola-outbreak-like-no-other.html (accessed on 26 April 2021).

29. Arino, J.; Jordan, R.; Van den Driessche, P. Quarantine in a multi-species epidemic model with spatial dynamics. Math. Biosci. 2007, 206, 46-60. [CrossRef]

30. Epstein, J.M.; Goedecke, D.M.; Yu, F.; Morris, R.J.; Wagener, D.K.; Bobashev, G.V. Controlling pandemic flu: The value of international air travel restrictions. PLoS ONE 2007, 2, e401. [CrossRef] [PubMed]

31. Colizza, V.; Vespignani, A. Epidemic modeling in metapopulation systems with heterogeneous coupling pattern: Theory and simulations. J. Theor. Biol. 2008, 251, 450-467. [CrossRef]

32. Espinoza, B.; Castillo-Chavez, C.; Perrings, C. Mobility restrictions for the control of epidemics: When do they work? PLoS ONE 2020, 15, e0235731. [CrossRef] [PubMed]

33. Poom, A.; Järv, O.; Zook, M.; Toivonen, T. COVID-19 is spatial: Ensuring that mobile Big Data is used for social good. Big Data Soc. 2020. [CrossRef]

34. Google Local Mobility Reports. Available online: https://www.google.com/covid19/mobility/ (accessed on 9 April 2021).

35. Moovitap Public Transit Statistics by Country and City. Available online: https://moovitapp.com/insights/en/Moovit_Insights_ Public_Transit_Index-countries (accessed on 9 April 2021).

36. Apple Mobility Trends Reports. Available online: https://covid19.apple.com/mobility (accessed on 9 April 2021).

37. What Can Traffic Data Tell Us about the Impact of the Coronavirus? Available online: https://www.tomtom.com/blog/movingworld/covid-19-traffic/ (accessed on 9 April 2021).

38. de Salud, M. MINSAL. Decimoséptimo Informe Epidemiológico Enfermedad por COVID-19. Departamento de Epidemiología. Available online: https://www.minsal.cl/wp-content/uploads/2020/05/Informe_EPI_15-05-20.pdf (accessed on 26 April 2021).

39. World Health Organization. COVID-19 Strategic Preparedness and Response Plan: Country Preparedness and Response Status for COVID-19; WHO: Geneva, Swizterland, 9 June 2020. Available online: https: / /www.who.int/publications/i/item/updatedcountry-preparedness-and-response-status-for-covid-19-as-of-9-june-2020 (accessed on 26 April 2021).

40. Step by Step Plan Government of Chile. Available online: https://www.gob.cl/coronavirus/pasoapaso/ (accessed on 9 April 2021).

41. Available online: https://interactives.lowyinstitute.org/features/covid-performance/ (accessed on 26 April 2021).

42. Grandata. Available online: https:/ / covid.grandata.com (accessed on 26 April 2021).

43. COVID-19 Data, Ministry of Sciences of Chile. Available online: https://github.com/MinCiencia/Datos-COVID19/blob/master/ output/producto1/Covid-19.csv (accessed on 26 April 2021).

44. Available online: http://www.dtpm.gob.cl/index.php/documentos/matrices-de-viaje (accessed on 26 April 2021).

45. Mobility and COVID-19 Data, Ministry of Sciences of Chile. Available online: https://github.com/MinCiencia/Datos-COVID1 9/tree/master/output/producto33 (accessed on 26 April 2021).

46. Universidad del Desarrollo. Indice de Mobilidad Pandemia COVID-19. Technical Report Instituto Data Science; Universidad del Desarrollo and Telefonica: Loreto Bravo, Chile, 2020.

47. Centro de Inteligencia Territorial 2012; Universidad Adolfo Ibanez: Santiago, Chile, 2012.

48. H3 Geospatial Indexing System. Available online: https://h3geo.org/docs (accessed on 9 April 2021).

49. Munizaga, M.A.; Palma, C. Estimation of a disaggregate multimodal public transport Origin-Destination matrix from passive smartcard data from Santiago, Chile. Transport. Res. Part C Emerg. Technol. 2012, 24, 9-18. [CrossRef]

50. Gschwender, A.; Munizaga, M.; Simonetti, C. Using smart card and GPS data for policy and planning: The case of Transantiago. Res. Transport. Econ. 2016, 59, 242-249. [CrossRef]

51. Set of Authorized, in Santiago, Cell-Phone Antennas. Available online: http:/ / datos.gob.cl/dataset/2019 (accessed on 26 April 2021). 
52. Available online: https://www.subtel.gob.cl/estudios-y-estadisticas/telefonia/ (accessed on 26 April 2021).

53. Available online: http://datascience.udd.cl/movilidad/ (accessed on 9 April 2021).

54. Aghabozorgi, S.; Ali Seyed, S.; Teh, Y.W. Time-Series Clustering? A Decade Review. Inform. Syst. 2015, 53, 16-38. [CrossRef]

55. Johnpaul, C.; Prasad, M.V.; Nickolas, S.; Gangadharan, G. Trendlets: A novel probabilistic representational structures for clustering the time series data. Expert Syst. Appl. 2020, 145, 113119. [CrossRef]

56. Paparrizos, J.; Gravano, L. Fast and accurate time-series clustering. ACM Trans. Database Syst. 2017, 42, 8:1-8:49. [CrossRef]

57. Rakthanmanon, T.; Campana, B.; Mueen, A.; Batista, G.; Westover, B.; Zhu, Q.; Zakaria, J.; Keogh, E. Searching and mining trillions of time series subsequences under dynamic time warping. In Proceedings of the 18th ACM SIGKDD International Conference on Knowledge Discovery and Data Mining, Beijing, China, 12-16 August 2012; pp. 262-270. [CrossRef]

58. Giorgino, T.; Tormene, P. dtw: Dynamic Time Warping Algorithms. Available online: http:/ /CRAN.R-project.org/package=dtw (accessed on 9 April 2021).

59. Available online: https:/ / cran.r-project.org/web/packages/dtwclust/index.html (accessed on 9 April 2021).

60. Arbelaitz, O.; Gurrutxaga, I.; Muguerza, J.; Perez, J.M.; Perona, I. An extensive comparative study of cluster validity indices. Pattern Recog. 2013, 46, 243-256. [CrossRef]

61. Saitta, S.; Raphael, B.; Smith, I.F. A bounded index for cluster validity. In International Workshop on Machine Learning and Data Mining in Pattern Recognition; Springer: Berlin/Heidelberg, Germany, 2007; pp. 174-187.

62. Kim, M.; Ramakrishna, R.S. New indices for cluster validity assessment. Pattern Recog. Lett. 2005, 26, 2353-2363. [CrossRef]

63. Jia, J.S. Population flow drives spatio-temporal distribution of COVID-19 in China. Nature 2020, 528, 389-394. [CrossRef] [PubMed]

64. Hufnagel, L.; Brockmann, D.; Geisel, T. Forecast and control of epidemics in a globalized world. Proc. Natl. Acad. Sci. USA 2004, 101, 15124-15129. [CrossRef] [PubMed]

65. Pei, S.; Kandula, S.; Shaman, J. Differential Effects of Intervention Timing on COVID-19 Spread in the United States. medRxiv 2020. [CrossRef]

66. Bennett, M. All things equal? Heterogeneity in policy effectiveness against COVID-19 spread in chile. World Dev. 2021, 137. [CrossRef]

67. Abadie, A.; Diamond, A.; Hainmueller, J. Comparative politics and the synthetic control method. Am. J. Political Sci. 2015, 59, 495-510. [CrossRef]

68. Ben-Michael, E.; Feller, A.; Rothstein, J. The Augmented Synthetic Control Method. Available online: https://arxiv.org/pdf/1811 .04170.pdf (accessed on 26 April 2021).

69. New England Complex Systems Institute. Countries Beating COVID-19. EndCoronavirus.org. 2021. Available online: https: / / www.endcoronavirus.org/countries\#winning (accessed on 3 February 2021). 